Article

\title{
Knock-Down the Expression of Brassinosteroid Receptor TaBRI1 Reduces Photosynthesis, Tolerance to High Light and High Temperature Stresses and Grain Yield in Wheat
}

\author{
Jingjing Fang ${ }^{1,2}$, Weiqi Zhu ${ }^{3}$ and Yiping Tong ${ }^{1, *}$ \\ 1 Institute of Genetics and Developmental Biology, Innovation Academy for Seed Design, \\ Chinese Academy of Sciences, Beijing 100101, China; fangjingjing@caas.cn \\ 2 National Key Facility for Crop Gene Resources and Genetic Improvement, Institute of Crop Science, \\ Chinese Academy of Agricultural Sciences, Beijing 100081, China \\ 3 The Zhao Xian Experimental Station of Hebei Academy of Agriculture and Forestry Sciences, \\ Shijiazhuang 050035, China; zwqkyj@163.com \\ * Correspondence: yptong@genetics.ac.cn; Tel.: +86-10-64806556
}

Received: 4 June 2020; Accepted: 1 July 2020; Published: 3 July 2020

\begin{abstract}
Brassinosteroid (BR)-deficient or -insensitive mutants exhibited altered plant architecture with the potential to impact yield, the underlying physiological and molecular mechanisms are still to be explored. In this study, we cloned three BR receptor homologous genes TaBRI1-A1, -B1 and -D1 from hexaploid wheat (Triticum estivum L.) and further isolated the TaBRI1-A1, TaBRI1-D1 deletion mutants from the ion beam-induced mutants of variety Xiaoyan81, TaBRI1-A1 and TaBRI1-D1 in which the expression of total receptor TaBRI1 was significantly decreased. The TaBRI1 knock-down mutants exhibited relatively erect leaves and a significant decrease in the 1000-grain weight. Further studies showed that TaBRI1 knock-down mutants showed a significant reduction in photosynthetic rate during the whole grain-filling stage. TaBRI1 knock-down plants generated by TaBRI1-A1, TaBRI1-D1 deletion or using virus-induced gene silencing exhibited the reduction in the efficiency of photosystem II (PSII) $\left(F v / F m, \Phi_{\mathrm{PSII}}\right.$ and electron transport rate, ETR) especially under high light and high temperature stresses. The 24-epibrassinolide (EBR) treatment increased $\mathrm{CO}_{2}$ assimilation rate in the wild type under both normal and high light and high temperature stresses conditions, but this increasing effect was not observed in the TaBRI1 knock-down mutants. Meanwhile, the expression levels of BR biosynthetic genes including TaDWARF4, TaCPD1 and TaCPD90C1 is not decreased or decreased to a lesser extent in the TaBRI1 knock-down mutants after EBR treatment. These results suggested that TaBRI1 is required for maintaining photosynthesis and tolerance to high light and high temperature stresses both of which are important for grain yield and will be a possible engineered target to control plant photosynthesis and yields in wheat.
\end{abstract}

Keywords: TaBRI1; photosynthesis; high light and high temperature stresses; grain yield; wheat

\section{Introduction}

Wheat is one of the most important crops in the world. Great efforts have been made to enhance its productivity and quality to meet the $1.6 \%$ increase of demand for wheat per year [1]. Plant hormone, brassinosteroids (BRs), play crucial roles in modulating plant architecture and seed yield. Treatment of rice plantlets with 24-epibrassinolide (EBR) leads to a $22 \%$ increase in seed fresh weight per plant [2]. In addition, brassinolide (BR) treatment promotes plant growth rate, root size and dry weight of root and stem [3]. BRs regulate plant development and gene expression through receptor kinase-mediated signal transduction pathway [4]. 
BR signaling pathway is well established in both Arabidopsis and rice in recent years and it was suggested that rice has a conserved BR primary signaling pathway with that of Arabidopsis [5]. In brief, BRs are perceived at the plasma membrane by the leucine-rich repeat (LRR) receptor kinase BRI1 (brassinosteroid insensitive 1) [6]. Binding of BRs induces BRI1 dissociation of the inhibitory protein BKI1 (BR kinase inhibitor 1), BRI1 autophosphorylation and association/transphosphorylation with co-receptor BAK1 which lead to the accumulation of non-phosphorylated BZR1 and BZR2/BES1 in the nucleus through a series of phosphorylation and dephosphorylation processes [7-10]. The non-phosphorylated BZR1 and BZR2/BES1 further directly or indirectly activates the expression of BR-responsive genes, thus regulating plant growth and development [11].

In addition to the functions in plant growth and development, BRs also play prominent roles in plant stress responses to various abiotic stresses such as low and high temperature, drought, salinity, organic pollutant and heavy metal toxicity [12-16]. The onset of abiotic stresses severely affects photosynthesis as the stresses lead to the over-reduction of the electron transport chain (ETC) which, in turn, results in photo-oxidation $[17,18]$. BRs have been shown to increase photosynthetic capacity by activating Rubisco activase. BR treatment activates antioxidant machineries in plants which scavenge the toxic reactive oxygen species (ROS) to protect plants from ROS damage [19-21].

Manipulation of BR signaling further revealed the potential role of BRs in plant responses to abiotic stresses. The negative regulator BIN2 and key transcription factors BZR2/BES1 are operated to regulate different stress responsive transcription factors which activate stress adaptive signaling pathways [22]. BR signaling is also implicated in salt and cold stress responses via BRI1 [23,24]. Previous studies showed the salt hypersensitivity of bri1-9 mutants could be partially rescued by inhibiting the endoplasmic reticulum-associated protein degradation system, suggesting that a membrane-bound BRI1 signaling complex is involved in the salinity response [23]. In addition, The bri1-9 mutant generates an increased tolerance to cold stress due to it could always be alert to stresses by constitutive activation of subsets of defense [24]. Taken together, these findings provide evidence that the abiotic stresses were regulated by BR receptors and downstream signaling components.

Accordingly, plant growth would be modified by manipulation of endogenous BR content or BR signaling. In most cases, BR-deficient or -insensitive mutants displayed dwarfism, erect leaf, delayed flowering, reduced fertility and grain length [6,25-28]. However, suppression of BR related genes involved in the biosynthesis and signaling pathways with a slight level could significantly enhance the grain yield in plant $[29,30]$. For example, CYP90B1/DWARF4 catalyzed the rate-limiting step of brassinosteroid biosynthesis, C-22 hydroxylation. The biomass and grain yield in osdwarf4-1 mutants are increased by nearly $40 \%$ and $26 \%$ compared with those in WT under high-density planting conditions, as the mutants show erect leaves and normal reproductive development [31]. The biomass of $d 61-7$, a weak mutant of OsBRI1, increase by $35 \%$ in biomass than wild type at a high planting density [32]. Moreover, partially suppression of endogenous OsBRI1 causes a 30\% increase in grain yield, compared with wild type at high density [32]. Plant height is another important agronomic trait that directly affects crop architecture and grain yields. Barley mutant of $H v B R I 1, u z u$, exhibited a semi-dwarf, upright plant architecture [33]. The $u z u$ gene is currently being introduced into all of the hull-less cultivars in Japan which is very suitable for high yields as its semi-dwarf phenotype is in favor of lodging resistance. Additionally, numerous BRI1 loss-of-function mutants have been identified in several species as well as Arabidopsis, including tomato (Lycopersicon esculentum), pea (Pisum sativum), rice (Oryza sativa) and Brachypodium distachyon [6,34-36]. These mutants exhibited similar pleiotropic phenotypes such as dwarfism, dark green leaves and photomorphogenesis in the dark which suggest that BRI1-mediated BR pathway are conserved in the plant development.

However, it has been reported that BR-deficient or -insensitive mutants exhibited altered plant architecture with the potential to impact yield, the underlying physiological mechanisms were remained unclear. Therefore, the main objectives of this study were (i) to examine the effects of deletion in BRI1 homologous genes on plant architecture and grain yield in wheat and (ii) to detect the putative biologic functions of TaBRI1 in regulating plant architecture and grain yield by measuring photosynthetic 
rate and assessing the tolerance ability to high light and high temperature stresses in TaBRI1 deletion mutants. This study provides substantial information for understanding the function of TaBRI1 in wheat.

\section{Materials and Methods}

\subsection{Plant Materials and Growth Conditions}

Common wheat (Triticum estivum L.) cv. Xiaoyan81 and TaBRI1 mutants were used in this study. The mutants were obtained from Xiaoyan81 deletion mutant library constructed by nitrogen ion irradiation [37]. Xiaoyan 81 is a winter wheat (Triticum estivum) variety which was released commercially in 2006.

Two connective field trials were conducted in 2013-2014 and 2014-2015 growing seasons at the Experimental Station of Institute of Genetics and Developmental Biology, Chinese Academy of Sciences, Beijing. The seeds of each material were grown in randomized blocks with three replications. The additives $18.0 \mathrm{~g} \mathrm{~m}^{-2}$ nitrogen $(\mathrm{N})$ in the form of urea and $9.0 \mathrm{~g} \mathrm{~m}^{-2}$ phosphorus $(\mathrm{P})$ as calcium superphosphate was supplied to the soil before sowing, and $5.2 \mathrm{~g} \mathrm{~m}^{-2}-\mathrm{N}$ was top-dressed at stem elongation stage. For each material in each replicate, 1000 seeds were sown in the $1.1 \times 5 \mathrm{~m}$ plot with six rows and the rows were spaced $15 \mathrm{~cm}$ apart. The plants were supplied with sufficient water to avoid potential drought stress throughout the growing season and sprayed with fungicide to prevent foliar diseases.

Hydroponic culture was used to evaluate the seedling phenotypes of TaBRI1 mutants. Hydroponic plants are also used for EBR treatment, analyzing the expression levels of TaBRI1 and BR biosynthetic genes, and evaluating the tolerance of wheat seedlings to high light and high temperature (HLHT) stresses. The seeds were surface sterilized and germinated on a sterile filter paper soaked with distilled water for 7 days at $20^{\circ} \mathrm{C}$. Subsequently, 24 seedlings were transferred to $25 \times 55 \mathrm{~cm}$ plastic boxes containing $14 \mathrm{~L}$ nutrient solution. The nutrient solution was composed as described by Ren et al. (2012) [38]. This solution was renewed every 3 days. The plants were grown in a controlled-environment growth chamber (HP-1000GS, Wuhan Ruihua Instrument \& Equipment Co., Ltd., Wuhan, China) with the following conditions: 14-h-light/10-h-dark photoperiod at $350-\mu \mathrm{mol} \mathrm{m}^{-2} \mathrm{~s}^{-1}$ photosynthetic photon flux density (PPFD) under $20^{\circ} \mathrm{C}$ with relative humidity of $60-70 \%$.

\subsection{Gene Cloning and Phylogenetic Analysis}

Using the protein sequence of rice BRI1 published in GenBank (AP014957.1) to blast wheat EST library, the obtained 50 ESTs were used to assembly the complete TaBRI1 sequence. Primers TaBRI1(F) and TaBRI1(R3) were designed at $5^{\prime}$ and $3^{\prime}$ ends, respectively to amplify the full length of TaBRI1 using Xiaoyan81 genomic DNA as template. The $3^{\prime}$-RACE PCR primer TaBRI1(RACE)F1 were designed according to the identified ESTs. According to the $3^{\prime}$-RACE results, the specific primers TaBRI1.1specific(R), TaBRI1.2specific(R) and TaBRI1.3specific(R) were designed on the $3^{\prime}$ UTR which were used to confirm the chromosome location of the genes and amplify the full length of TaBRI1-A1, $-D 1$ and $-B 1$, respectively.

A phylogenetic tree of TaBRI1 was generated (using the same software) by the neighbor-joining (NJ) method with Poisson correction [39]. All positions which contain alignment gaps were removed by the NJ analyses with pairwise sequence comparisons. Bootstrap replication (1000 replications) was used to quantify statistical support for the nodes in the phylogenetic tree.

\subsection{Screening for TaBRI1-A1, TaBRI1-D1 Deletion Mutants}

Genomic DNA samples were prepared from 5600 seedlings grown from randomly selected $\mathrm{M}_{2}$ seeds for screening the deletion mutants of TaBRI1. TaBRI1.1(specific)R (A chromosome specific primers) and TaBRI1.2(specific)R (D chromosome specific primers) obtained from $3^{\prime}$-RACE were mixed together with TaBRI1(RACE)F1 to amplify using DNA of Xiaoyan81 ion beam mutagenesis population as 
template. The above primer sets amplified two fragments with different sizes, which were specific for the TaBRI1-A1 (519 bp) and TaBRI1-D1 (555 bp) genes of Xiaoyan81, respectively. According to the sizes of amplified fragments, deletion mutants of TaBRI1 on chromosome $A$ and chromosome $D$ were obtained, respectively.

\subsection{Vector Construction and Transformation}

The coding fragments of TaBRI1-A1, $-B 1$ and $-D 1$ were amplified with primers TaBRI1(pri)F and TaBRI1(pri)R using the obtained TaBRI1-A1, $-B 1$ and -D1 complete genomic sequence as templates, due to there are no introns for TaBRI1 genomic sequence. The fragments were inserted into pEASY-blunt vector and digested with NdeI and BamHI. The fragment was then inserted into the pRI-101 vector by digesting with NdeI and BamHI. bri1-5 mutants were used as receptor plants for transformation using the floral dip method. Seeds of wild-type (WT) Col-0, bri1-5 and overexpression lines in bri1-5 mutant background were germinated on half-strength Murashige and Skoog medium and transferred into soil for continuing growth at $22{ }^{\circ} \mathrm{C}$ under a 16-h-light/8-h-dark photoperiod.

\subsection{Leaf Angle Measurements}

The leaf angle during the grain-filling stage was measured with a protractor. The measurements were made in one plant at several different stages after an-thesis. Data were collected from fifteen flag leaves that were fully expanded in the center of each plot at every stage. The second-leaf angle at the seedling stage was measured with the method using three-week old seedlings.

\subsection{Gas Exchange Measurements}

$\mathrm{CO}_{2}$ gas exchange of leaves was measured with a portable LI-6400 photosynthesis system (LiCor-6400; LiCor, Inc., Lincoln, NE, USA) during post-anthesis period. The LI-6400 was operated as an open system. The measurement conditions were $450-\mu \mathrm{mol} \mathrm{s}{ }^{-1} \mathrm{CO}_{2}$ in the leaf chamber, $1200 \mu \mathrm{mol} . \mathrm{m}^{-2} \mathrm{~s}^{-1}$ PPFD and $25^{\circ} \mathrm{C}$ of the temperature. Eight fully expanded flag leaves in the center of each plot were measured from 9:00 to 11:00 in the morning on a sunny day.

To evaluate the tolerance of wheat seedlings to HLHT stresses, WT and TaBRI1 mutants were hydroponic cultured for 12 days according to the above method described in Section 2.1. The uniform plants were selected and then were exposed to white light provided by a halogen lamp (Flecta, Frankfurt, Germany). The leaves were exposed constantly to high light (1500- $\mu \mathrm{mol} \mathrm{m}^{-2} \mathrm{~s}^{-1}$ PPFD on the leaf surface) under high temperature $\left(35 \pm 1{ }^{\circ} \mathrm{C}\right)$ with a relative humidity $60 \%$ for $3 \mathrm{~h}$. Leaves were equilibrated for at least $3 \mathrm{~min}$ and $\mathrm{CO}_{2}$ assimilation rate (A), stomatal conductance (Gs), transpiration rate $(\mathrm{E})$ and intercellular $\mathrm{CO}_{2}$ concentration $(\mathrm{Ci})$ were recorded at a $\mathrm{CO}_{2}$ concentration of $380-\mu \mathrm{mol} \mathrm{m} \mathrm{m}^{-2} \mathrm{~s}^{-1}$ and at a temperature $22{ }^{\circ} \mathrm{C}$ with a relative humidity $60 \%$ and a light intensity of $500 \mu \mathrm{mol} \mathrm{m}{ }^{-2} \mathrm{~s}^{-1}$ before and after the treatment.

\subsection{Virus-Induced Gene Silencing (VIGS) Assay}

To construct recombinant BSMV:TaBRI1 vector, the $258 \mathrm{bp}$ cDNA fragments of TaBRI1 were amplified using primers 5' -AGCTAGCCAGAGCTTGGTTCTC-3' and 5' - TGCTAGCGGTACTTGCCTCATC-3' and subcloned in an antisense orientation into the Nhe I restriction site of the RNA $\gamma$ of BSMV. For in vitro transcription, the $B S M V \alpha, B S M V: G F P$ and $B S M V: T a B R I 1$ vectors were linearized with Mlu I, and $B S M V \beta$ with SpeI which were used as templates to synthesize RNAs with the RiboMAXTM large scale RNA production system (Promega, Madison, WI, USA). The $\alpha, \beta, \gamma$ RNAs were mixed in equal amounts and then diluted with GKP buffer (0.05-mol/L glycine, 0.03-mol/L K ${ }_{2} \mathrm{HPO} 4,1 \%$ w/v bentonite and $1 \%$ w/v Celite at $\mathrm{pH}$ 9.2). The inoculation of each viral construct was performed according to previously described [40]. Briefly, the virus BSMV:TaBRI1 and control virus BSMV:GFP were used to inoculate with the second fully expanded leaves from the bottom at 2-leaf stage. The incubated plants were grown at $90 \%$ relative humidity with darkness for $24 \mathrm{~h}$ at $23 \pm 1{ }^{\circ} \mathrm{C}$ then grown under a 16 -h -light/8-h-dark photoperiod. 


\subsection{Imaging Analysis of Chlorophyll Fluorescence}

Flag leaves from WT and TaBRI1 knock-down mutants were sampled at 21 days post-anthesis (DPA) and 28 DPA in the field. The flag leaves were detached, placed on moist gauze and then exposed to HLHT conditions supplied with high-light growth chamber (E36HO, Percival Scientific, Perry, IA, USA). The light reaching the leaf surface was $1500-\mu \mathrm{mol} \mathrm{m} \mathrm{m}^{-2} \mathrm{~s}^{-1}$ PPFD under $35^{\circ} \mathrm{C}$ for $3 \mathrm{~h}$ with a relative humidity ca. $60 \%$. The leaves were taken care to keep moist throughout the treatment. Chlorophyll fluorescence imaging of the flag leaves was measured using an imaging-PAM fluorometer (Walz, Effeltrich, Germany). Leaves were placed in darkness for $30 \mathrm{~min}$ prior to measurement. Maximum quantum yield of PSII ( $F v / F m)$, actual photochemical efficiency of PSII ( $\left.\Phi_{\text {PSII }}\right)$ and electron transport rates (ETRs) were measured and calculated as described previously [41]. False-color images representing $F v / F m$ and $\Phi_{\text {PSII }}$ levels in WT and mutant leaves were produced using the PAM software equipped with the imaging-PAM fluorometer.

\subsection{RNA Extraction and Quantitative RT-PCR}

Total RNA was extracted from wheat leaf samples using Trizol (Invitrogen, Waltham, MA, USA) and pretreated with DNase I. Two micrograms total RNA was used to synthesize the first-strand cDNA using Superscript III reverse transcriptase (Promega) following the manufacturer's instructions. Using the protein sequence of rice DWARF4, CPD1 and CPD90D1 published in GenBank to blast wheat EST library, the obtained ESTs were used to assembly and primers were designed on the coding sequence (CDS). The SYBR Premix Ex Taq (TaKaRa; RR041A) was used to conduct the real-time PCR analysis on an ABI7900 HT fast real-time PCR system. cDNA product was used as template for 40 cycles of $95^{\circ} \mathrm{C}$ for $30 \mathrm{~s}, 95^{\circ} \mathrm{C}$ for $10 \mathrm{~s}$ and $60^{\circ} \mathrm{C}$ for $30 \mathrm{~s}$. The expression levels of TaBRI1 and BR biosynthetic genes were normalized to ACTIN1 gene and calculated using the $2^{-\Delta \Delta C T}$ method. RT-PCR was repeated at least 3 times for each sample and the used primers were listed in Table S1.

\subsection{EBR Treatment}

After hydroponic culturing for 12 days according to the above method Section 2.1, the uniform plants were selected and treated with 24-epibrassinolide (EBR). The seedling leaves were sprayed with 0.1-mg/L EBR until they were completely wet. The control leaves were sprayed with the same concentration of ethanol $(1 / 1000, v / v)$ as the EBR was dissolved in ethanol when preparing the stock solution. After $48 \mathrm{~h}$ of EBR treatment, the seedlings were exposed to HLHT stresses for $3 \mathrm{~h}$. The fully expanded second leaves were used for gas exchange measurements and gene expression analysis.

\subsection{Statistical Analysis}

All data in this study were presented as mean \pm standard error (SE) or deviation (SD). Statistically significant differences was tested with SPSS software at $p=0.05$ using ANOVA, post hoc LSD.

\section{Results}

\subsection{Cloning of Three TaBRI1 Homologous Genes and the Expression Pattern of TaBRI1}

The full-length cDNA and genomic sequences of TaBRI1 were obtained through 3'-RACE (rapid amplification of cDNA end) PCRs and genomic amplified, respectively, from the winter wheat variety Xiaoyan81. Comparison of the genomic DNA and cDNA sequences revealed that the TaBRI1 gene structure contains no introns and had large variations in the $3^{\prime}$-UTRs. Use the gene specific primers located at the $3^{\prime}$-UTRs and the Chinese Spring deletion lines to identify the chromosome location of the genes, the results showed that these three TaBRI1 genes were mapped on chromosomes 3A, 3B and 3D (Figure 1A). Phylogenetic analysis indicated that the three TaBRI1 $s$ fall into the same clade with OsBRI1 of rice and HvBRI1 of barley and were closely related to HvBRI1 (Figure 1B). 

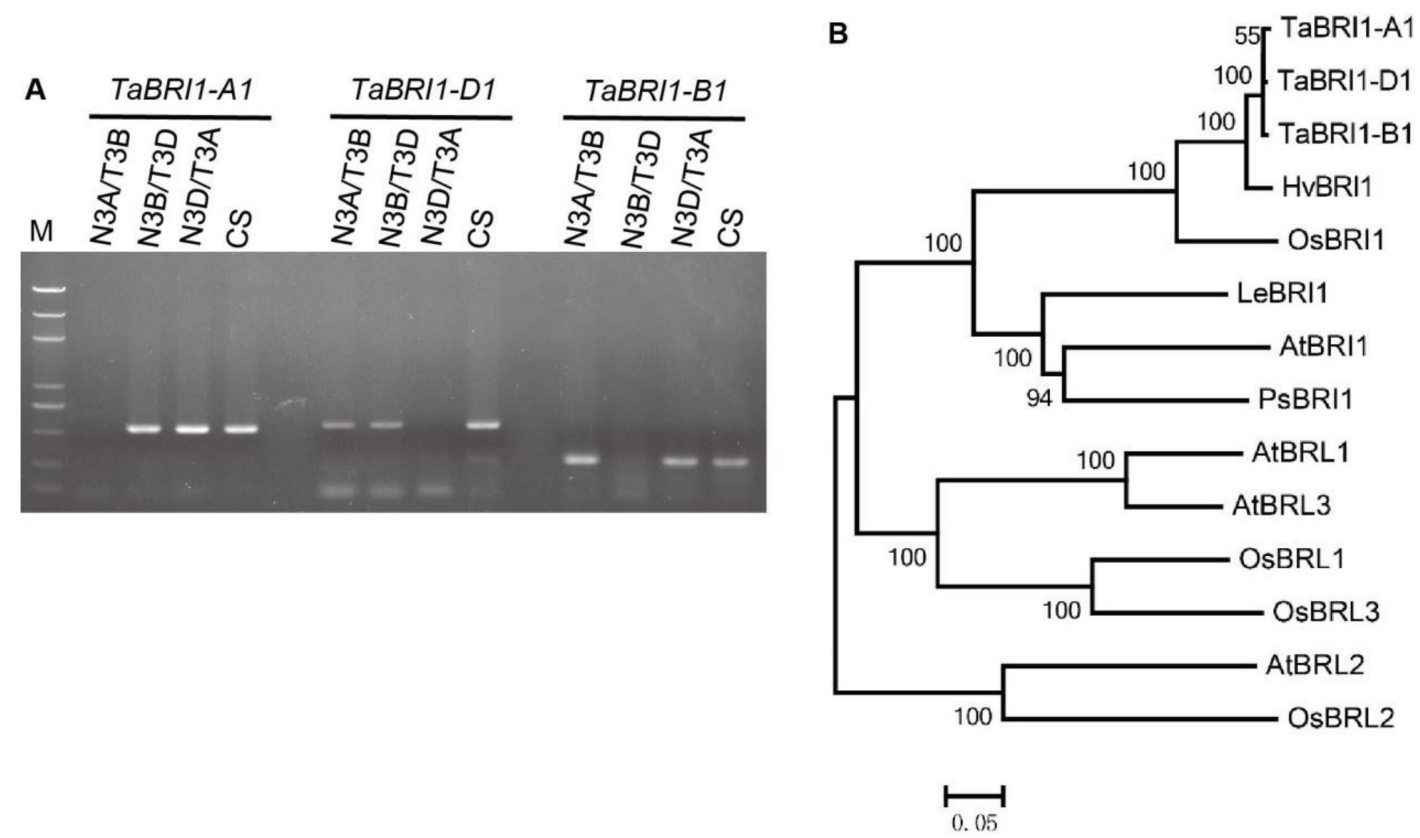

Figure 1. Chromosome location of TaBRI1 and phylogenetic analysis. (A) Chromosome location of TaBRI1 using nulli-tetrasomic and double ditelosomic lines derived from wheat cultivar Chinese Spring (CS). M, DL2000 DNA marker; N3A/T3B, N3B/T3D, N3D/T3A, three nulli-tetrasomic lines; (B) phylogenetic analysis of protein sequences of TaBRI1 and other BRI1 from barley, rice, tomato, pea and Arabidopsis. The numbers on the branches presented refer to the degree of shared sequence similarity. The comparison included the following BRI1 family members: for barley, HvBRI1 (BAD06331); for rice, OsBRI1 (BAB68053), OsBRL1 (BAD34326), OsBRL2 (AAK52544) and OsBRL3 (BAD01717); for tomato, LeBRI1 (AAN85409); for pea, PsBRI1 (BAC99050); and for Arabidopsis, AtBRI1 (AAC49810), AtBRL1 (Q9ZWC8), AtBRL2 (Q9ZPS9) and AtBRL3 (Q9LJF3).

Real-time RT-PCR analysis showed that TaBRI1 was universally expressed in all tissues, with relatively high expression in lamina joint, stem, root and rachis (Figure 2A). To investigate the biology function of TaBRI1, we overexpressed TaBRI1 in the bri1-5 mutant, an ideal material for BRI1 complementation studies, due to it is a weak mutant allele of Arabidopsis BRI1, semi-dwarf and setting nearly normal amount of seeds, compared to null alleles of bri1 mutants. As shown in the Figure 2B, the transgenic plants exhibited nearly complete complementation of the bri1-5 mutant phenotypes, resembling the phenotype of the WT. This indicated that there was functional conservation of BRI1 between the monocot plant, wheat and the dicot plant, Arabidopsis.

\subsection{TaBRI1-A1 or TaBRI1-D1 Deletion Mutants with a Decreased TaBRI1 Expression Exhibited Relatively Erect Leaves}

We isolated the TaBRI1 deletion mutants from the ion beam-induced mutants of variety Xiaoyan81. By fragment analysis of PCR products, putative homozygous mutants lacking TaBRI1-A1 and -D1 were detected in two (K51 and L75) and one (B33) independent $\mathrm{M}_{2}$ families, respectively. Before further analysis, homozygous TaBRI1 mutants (TaBRI1-A1, K51; TaBRI1-D1, B33) were backcrossed with their WT progenitor Xiaoyan81. The homozygous deletion lines $\mathrm{BC}_{1} \mathrm{~F}_{2}$ were used to analyze the expression level of TaBRI1. The qRT-PCR results showed that the TaBRI1 expression was significantly reduced in the TaBRI1-A1 or TaBRI1-D1 deletion mutants using primers designed from conserved regions of TaBRI1 homologous genes, compared with WT, Xiaoyan81 (Figure 3A). TaBRI1-A1 and -D1 transcripts were not detected in their corresponding mutants (Figure $3 \mathrm{~B}$ ), suggesting that they were deleted in their corresponding mutants. 

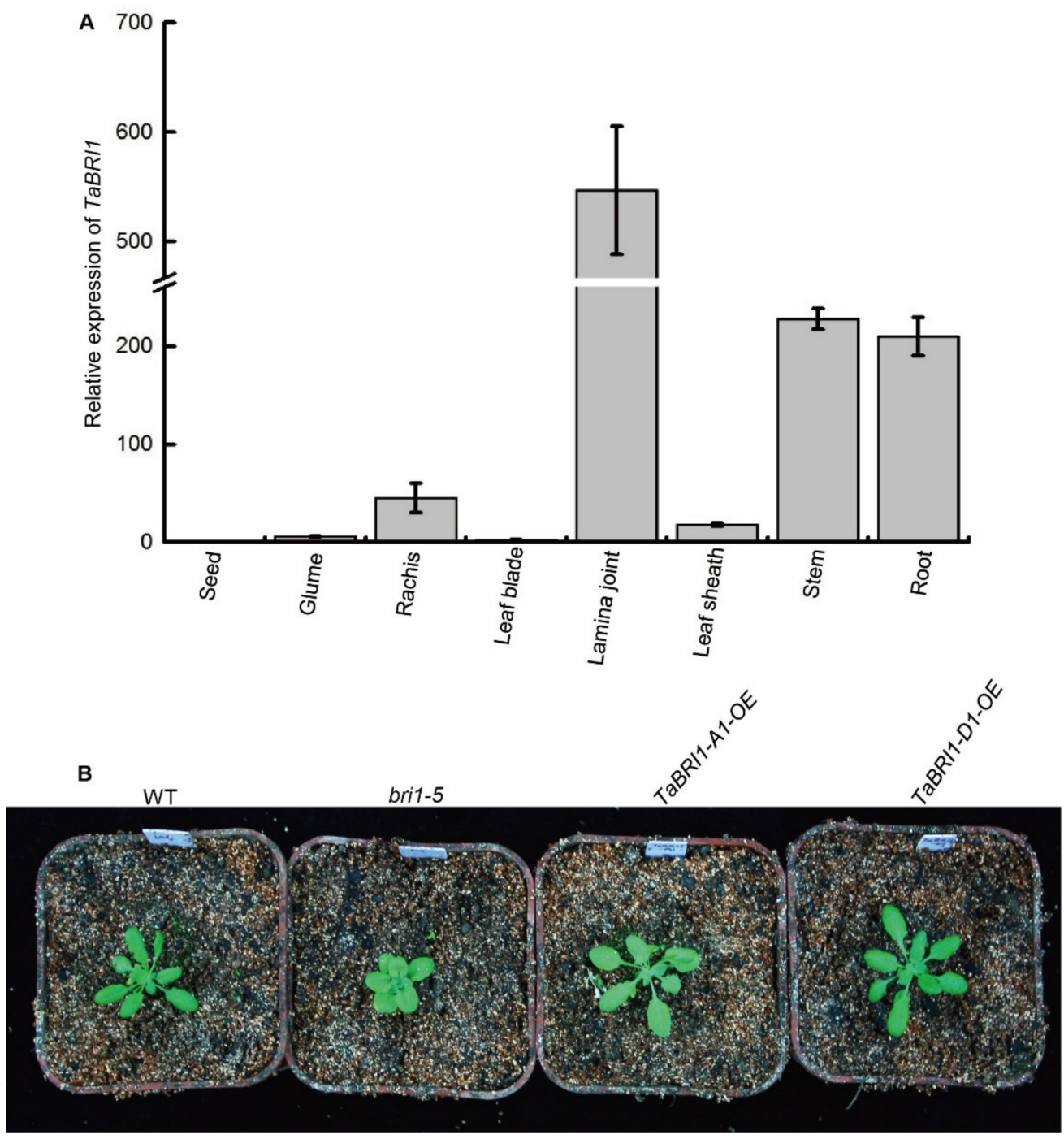

Figure 2. Expression pattern of TaBRI1 gene and complementation analysis in the Arabidopsis bri1-5 mutant by expressing TaBRI1. (A) Expression of TaBRI1 in various tissues analyzed by real-time PCR. Various tissues were collected from plants at the reproductive stage. Each tissue had three biologic replicates and each biologic replicate comprised a pool of five plants; (B) complementation analysis in the Arabidopsis bri1-5 mutant by expressing TaBRI1-A1 and -D1, respectively.

In TaBRI1 knock-down mutants, the second leaf angle was significantly decreased compared with that of WT at the seedling stage. The angles of the second leaf of WT, TaBRI1-A1 and TaBRI1-D1 were averaged $55 \pm 1^{\circ}, 23 \pm 2^{\circ}$ and $34 \pm 2^{\circ}$, respectively (Figure 3C,D). Previous studies have shown that the rice bri1 mutant of brassinosteroid receptor exhibited an erect leaf phenotype [6]. To further clarify the effect of TaBRI1-A1 or TaBRI1-D1 deletion on plant architecture in wheat, we tracked the plant type of the mutant from wheat seedling to the maturity in the field. The results showed that at the early jointing stage, the plant architecture of TaBRI1-A1 mutant was compact, compared that of WT Xiaoyan81 which was loosed (Figure 3E,F). The plant architecture of TaBRI1-D1 mutants showed weak morphologic phenotypes with less erect leaves (Figure 3G). The flag leaf of WT Xiaoyan81 possesses the characteristic of changing from erect to droopy posture. Consistent with this, in our study the flag leaf angle of Xiaoyan 81 was $30^{\circ}$ at flowering stage (0 DPA) and increased to $72^{\circ}$ at 7 DPA (Figure $4 \mathrm{~A}, \mathrm{~B}$ ). At 14 DPA, the flag leaf of Xiaoyan81 exhibited droopy posture with $146^{\circ}$ of the leaf angle at maturity (30 DPA) (Figure 4A,B). The increasing leaf angle with plant growth was also observed on the flag leaves of TaBRI1-A1 and TaBRI1-D1 mutants, however, the mutants exhibited slower increasing rates 
than Xiaoyan81 did during the whole post-anthesis period (Figure 4A,B). Consequently, until the late post-anthesis stage (21 DPA-28 DPA), the flag leaves of TaBRI1 mutants change into flat posture and at maturity (30 DPA) the leaf angle was $110^{\circ}$ to $129^{\circ}$, exhibiting significant reduction compared to that in WT (Figure 4A,B).
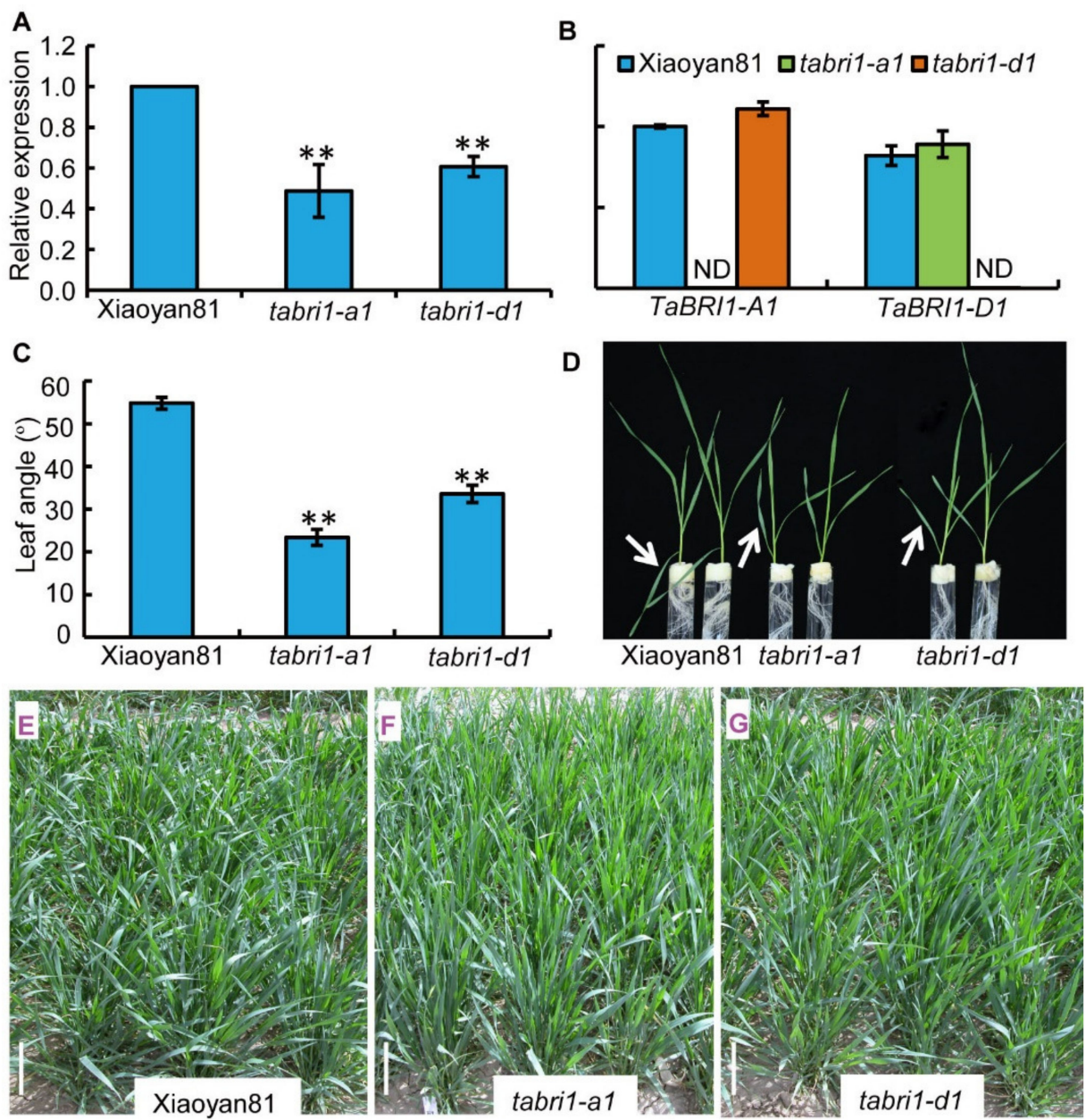

Figure 3. Angle between leaf blade and leaf sheath of wild-type (WT) Xiaoyan81 and TaBRI1 mutants at seedling stage. (A) Relative expression levels of total TaBRI1 genes in WT and TaBRI1 mutants at seedling stage. Each genotype had three biologic replicates, and each biologic replicate comprised a pool of five plants. ** indicates significant differences between WT and TaBRI1 mutants at $p<0.01$; (B) relative expression levels of TaBRI1-A1 and -D1. Each genotype had three biologic replicates and each biologic replicate comprised a pool of five plants; (C) leaf angle in WT and TaBRI1 mutants. Each genotype had three biologic replicates, and each biologic replicate comprised fifteen plants; (D) Leaf morphology. The leaf of WT (left) is bent at the lamina joint indicated by the white arrow, whereas the leaves of TaBRI1-A1 (center) and TaBRI1-D1 (right) mutants are more erect; (E-G) morphology of WT, TaBRI1-A1 and TaBRI1-D1 mutants in the field at the seedling stage. Bars $=10 \mathrm{~cm}$. 

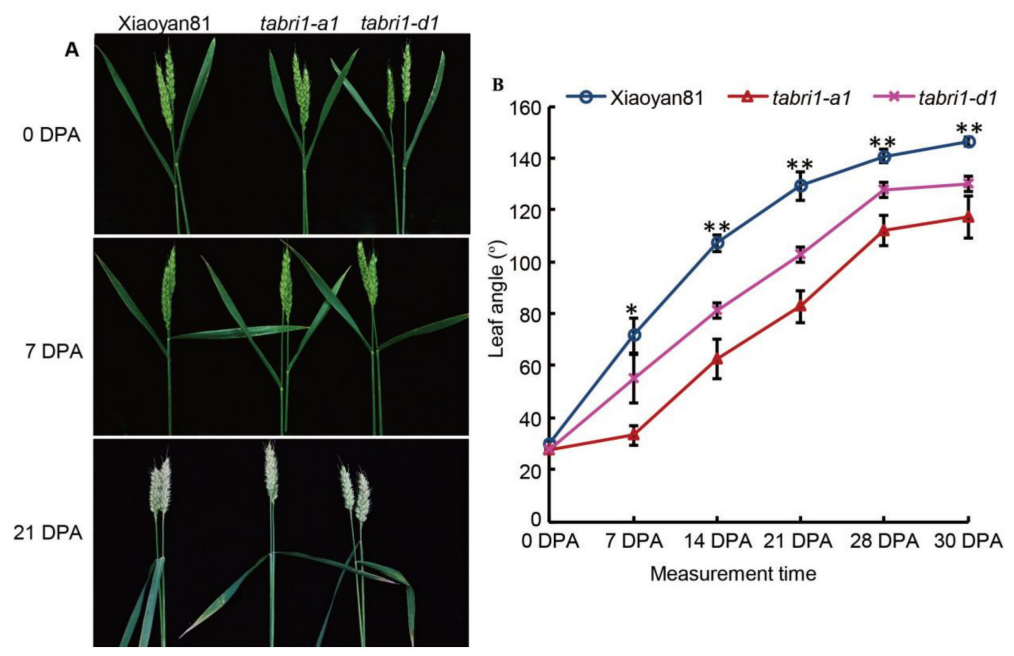

Figure 4. Kinetic comparison of leaf angle between the flag leaf blade and its sheath of WT and TaBRI1 mutants at the post-anthesis stage. (A) Flag leaf morphology; (B) leaf angle in WT and TaBRI1 mutants during the whole post-anthesis period. Each genotype had three biologic replicates, and each biologic replicate comprised fifteen plants. ${ }^{*}$ and ${ }^{* *}$ indicate significant differences between WT and TaBRI1 mutants at $p<0.05$ and $p<0.01$, respectively.

\subsection{TaBRI1 Knock-Down Mutants Showed a Reduction in Grain Yield}

Yield performance of TaBRI1 knock-down mutants, TaBRI1-A1 and TaBRI1-D1 in the field was further analyzed. The TaBRI1 knock-down mutants showed a significant reduction in plant height (Figure 5A,B). However, no significant differences were observed in the spike number per plant and number of grains per spike between WT and TaBRI1 knock-down mutants, there is a significant reduction in the 1000-grain weight (TGW), leading to a decrease in grain yield per plant (Figure 5C, Supplementary Materials Figure S4). In addition, TaBRI1 knock-down mutants had a significant reduction in the harvest index compared with WT (Figure 5D). Overall, these observations indicated that TaBRI1 modifies plant height and reduces TGW.
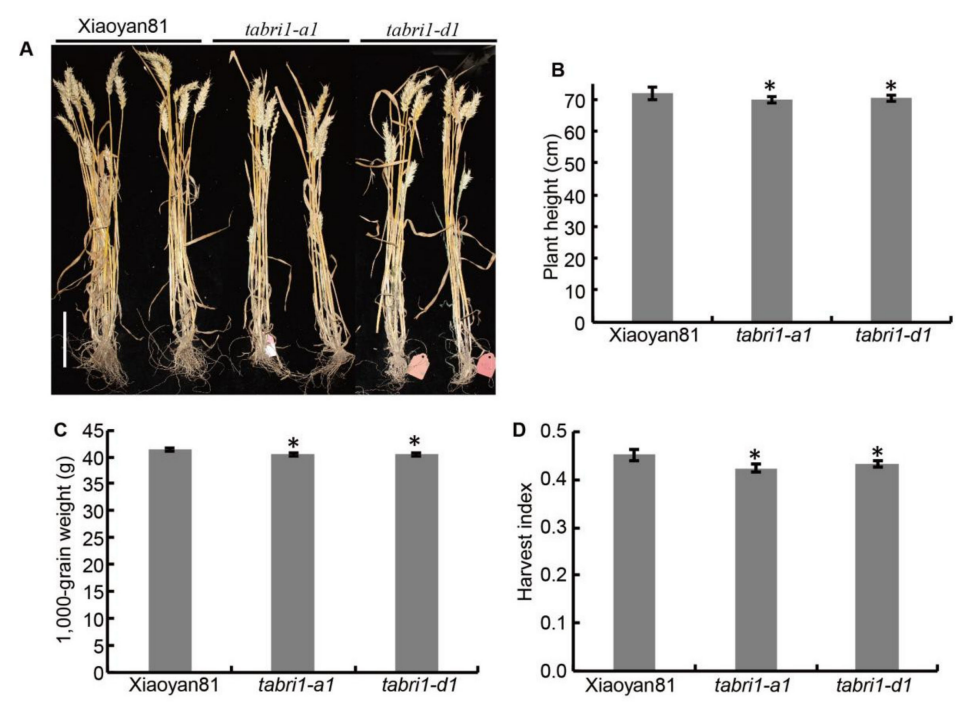

Figure 5. The yield traits in WT, TaBRI1-A1 and TaBRI1-D1 mutants. (A) Phenotypes of TaBRI1-A1 and TaBRI1-D1 mutants at maturity. Bar $=15 \mathrm{~cm}$; (B) plant height; (C) 1000-grain weight; (D) Harvest index. All phenotypic data were measured from field-grown plants under normal cultivation conditions. Each genotype had three biologic replicates, and each biologic replicate comprised fifteen plants. * indicates significant differences between WT and TaBRI1 mutants at $p<0.05$. 


\subsection{TaBRI1 Knock-Down Mutants Showed a Reduction in Photosynthetic Rate}

The flag leaf is generally considered as the major source of photosynthetic products in panicles as flag leaves after flowering produced over $50 \%$ carbohydrates that accumulate in grains of cereals such as rice [42-45]. To explore the reason for the reduction of TGW, net photosynthesis in the flag leaves of WT, TaBRI1-A1 and TaBRI1-D1 were measured during the grain filling stage. The results showed that TaBRI1 knock-down mutants, TaBRI1-A1, TaBRI1-D1 generally had lower $\mathrm{CO}_{2}$ assimilation rate than the WT (Figure 6). At the flowering stage (0 DPA) and 7 DPA, the $\mathrm{CO}_{2}$ assimilation rate in the TaBRI1-A1 mutants was significantly decreased, compared with that in WT. However, there was no significant difference between the TaBRI1-D1 and WT at the above stages. At 14 DPA, the TaBRI1-A1 and TaBRI1-D1 mutants both exhibited significantly lower $\mathrm{CO}_{2}$ assimilation rate than WT. After 14 DPA, the $\mathrm{CO}_{2}$ assimilation rate of WT and TaBRI1 knock-down mutants started to decrease, but the TaBRI1 knock-down mutants exhibited faster decreasing rates than the WT did, consequently the TaBRI1 knock-down mutants had significantly lower $\mathrm{CO}_{2}$ assimilation rate than WT (Figure 6).

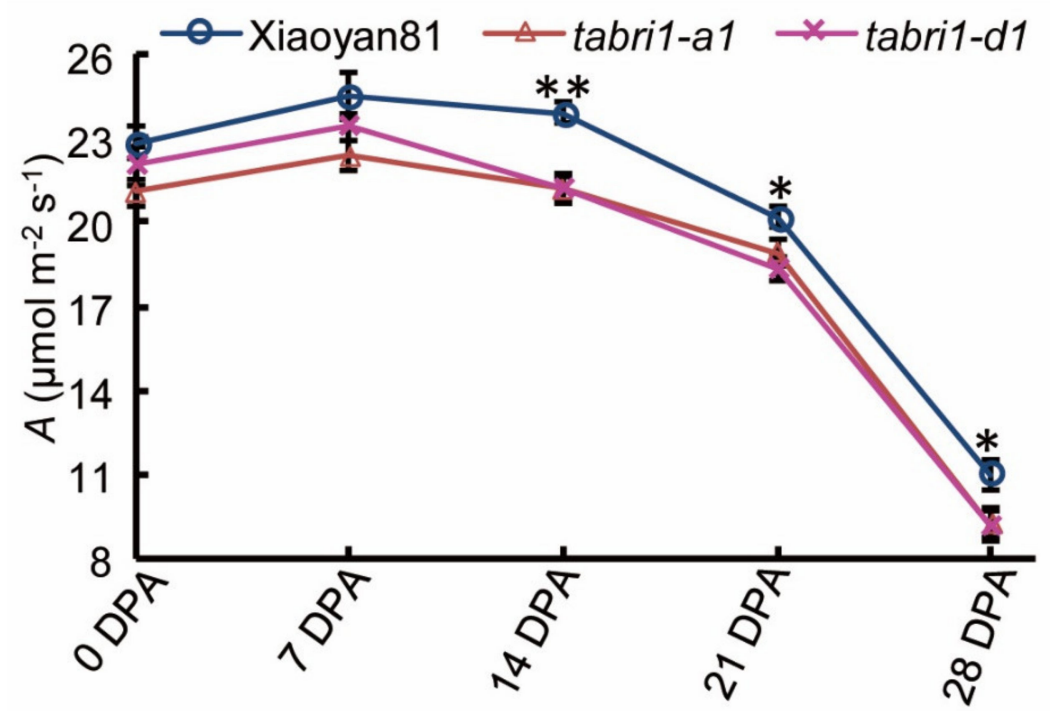

Figure 6. Photosynthesis parameters in WT, TaBRI1-A1 and TaBRI1-D1 mutants during the whole post-anthesis period. $\mathrm{CO}_{2}$ assimilation rate, A. Each genotype had three biologic replicates at each measurement time, and each biologic replicate comprised eight plants. ${ }^{*}$ and ${ }^{* *}$ indicate significant differences between WT and TaBRI1 mutants at $p<0.05$ and $p<0.01$, respectively.

3.5. TaBRI1 Knock-Down Plants Generated by TaBRI1-A1, TaBRI1-D1 Deletion or Using Virus-Induced Gene Silencing Exhibited the Reduced Tolerance to High Light and High Temperature Stresses

Wheat plants often suffer high light and high temperature (HLHT) stresses at the late grain filling stage in Northern China Plain. High light accompanied with other adverse environments such as high temperature and/or drought will eventually lead to irreversible photooxidation of photosynthetic apparatus which will decrease photosynthetic function [46]. We further explored the role of TaBRI1 in wheat response to HLHT stresses. The chlorophyll fluorescence parameters in the detached flag leaves were compared between WT and TaBRI1 knock-down mutants, TaBRI1-A1 and TaBRI1-D1, under HLHT stresses at 14 and 21 DPA. At 14 and 21 DPA, WT and TaBRI1 knock-down mutants showed similar values of maximum photochemical efficiency $(\mathrm{Fv} / \mathrm{Fm})$ and actual photochemical efficiency of PSII ( $\left.\Phi_{\text {PSII }}\right)$ before high light and high temperature (HLHT $0 \mathrm{~h}$ ); after the detached flag leaves were treated with HLHT for $3 \mathrm{~h}$ (HLHT $3 \mathrm{~h}$ ), the values of Fv/Fm and $\Phi_{\mathrm{PSII}}$ were reduced and exhibited lower levels in the TaBRI1 knock-down mutants than in the WT (Figures 7 and 8). At 21 DPA, more obvious reduction in the $F v / F m$ and $\Phi_{\mathrm{PSII}}$ values were observed in TaBRI1 knock-down mutants, compared with that in WT (Figure 8). The above results indicated that TaBRI1 is required for resistance to HLHT stresses in wheat. 

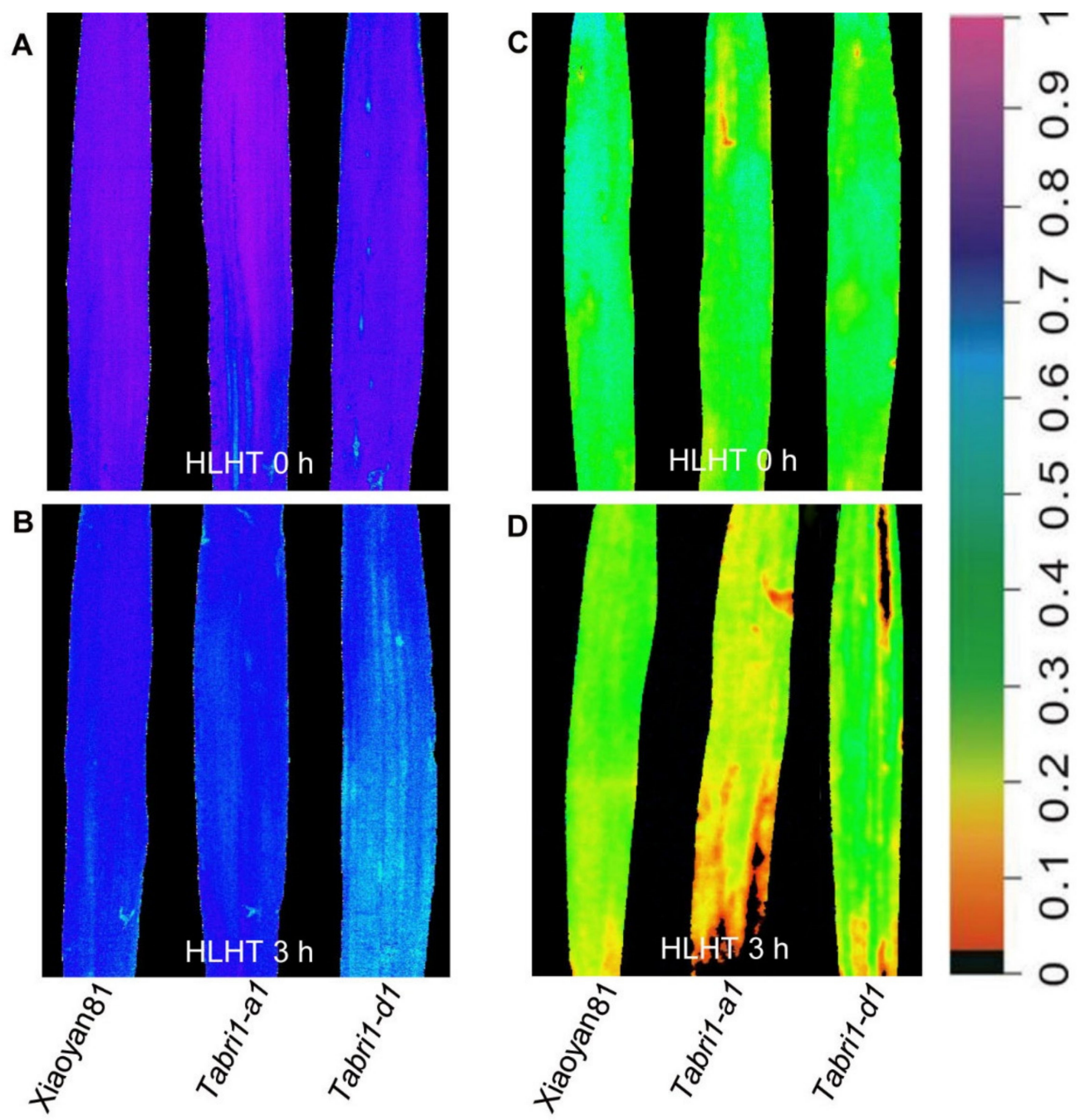

B

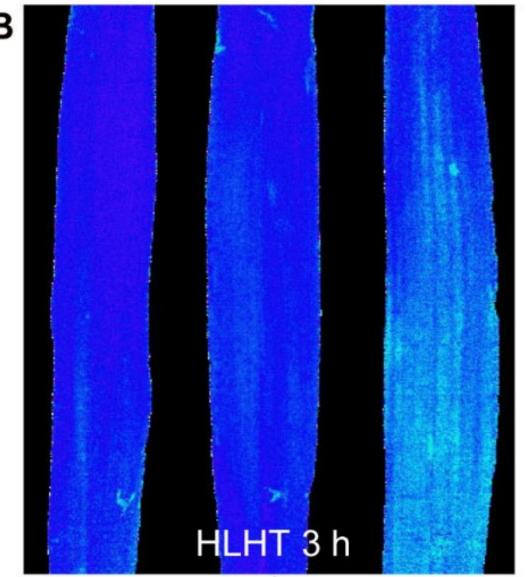<smiles>CC(C)=C1CCCCC1</smiles>

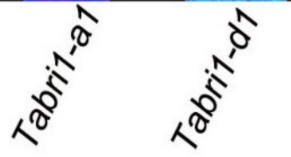

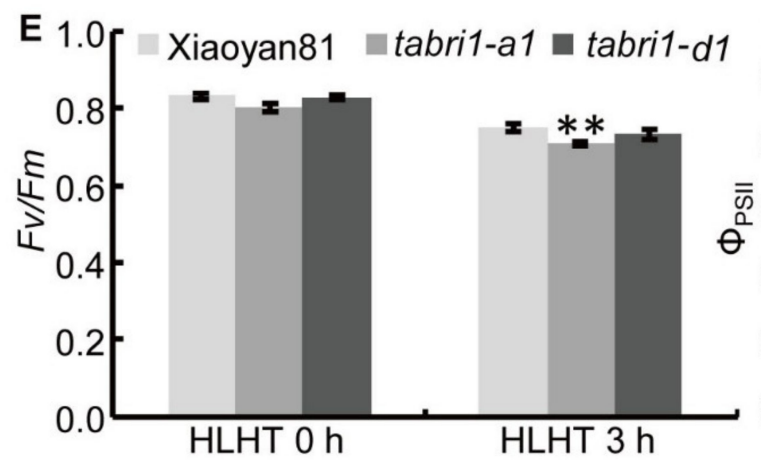

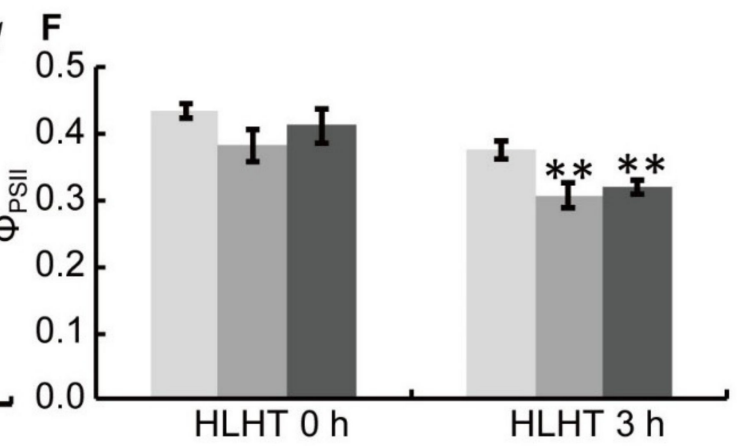

Figure 7. Chlorophyll fluorescence parameters of detached flag leaves in WT and TaBRI1 mutants at 14 DPA under HLHT $3 \mathrm{~h}$. (A-D) Images of the maximum photochemical efficiency $(F v / F m)(\mathbf{A}, \mathbf{B})$, the actual PSII efficiency ( $\left.\Phi_{\text {PSII }}\right)(\mathbf{C}, \mathbf{D})$ of WT and TaBRI1 mutants under high light and high temperature (HLHT) $3 \mathrm{~h}$. The color in (A-D) represents the value of each parameter in the color scale. (E,F) Statistic analysis of $F v / F m, \Phi_{\text {PSII }}$ in (A-D), respectively. Data from three biologic replicates, and each biologic replicate comprised eight plants. ${ }^{* *}$ indicates significant differences between WT and TaBRI1 mutants at $p<0.01$. 
A

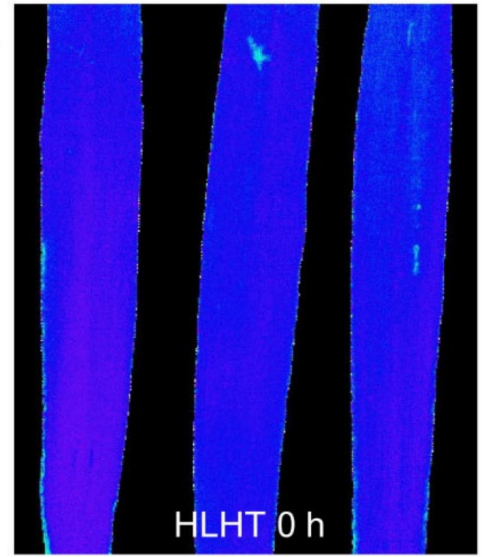

B

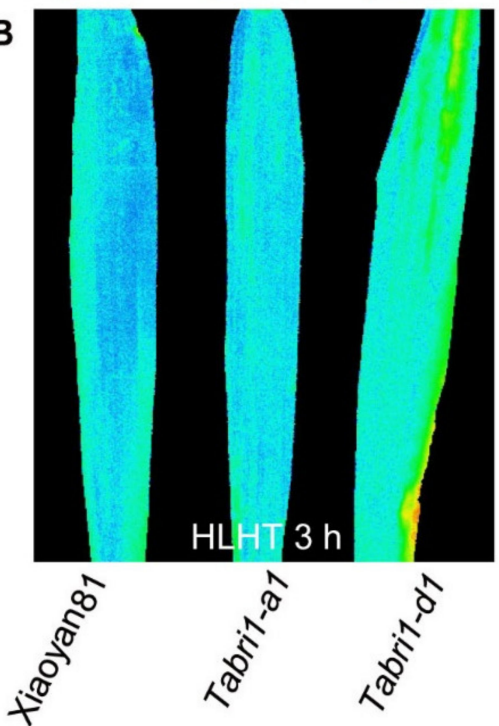

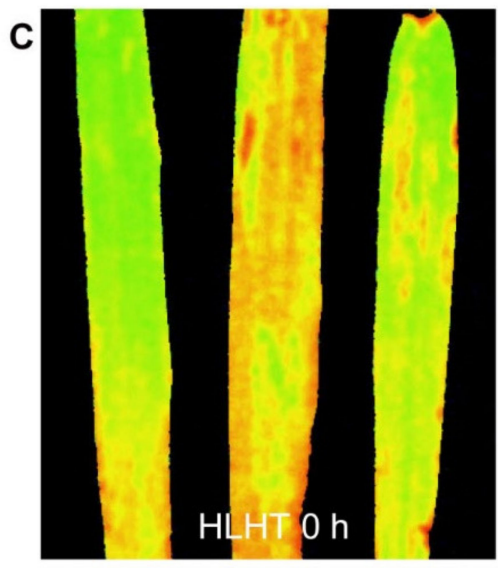

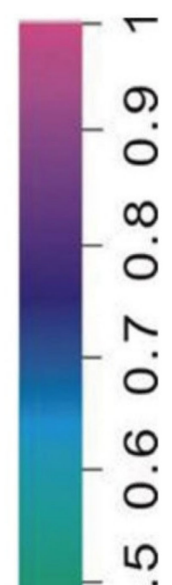

D

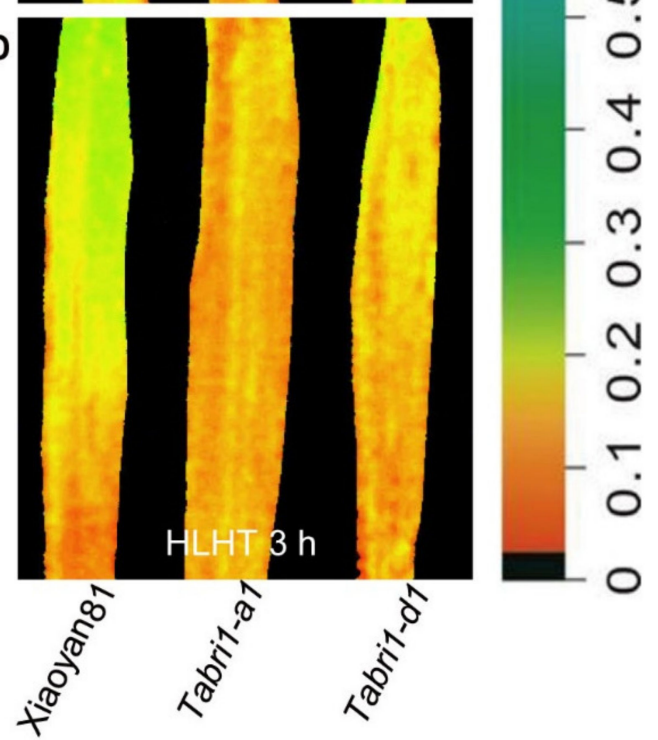

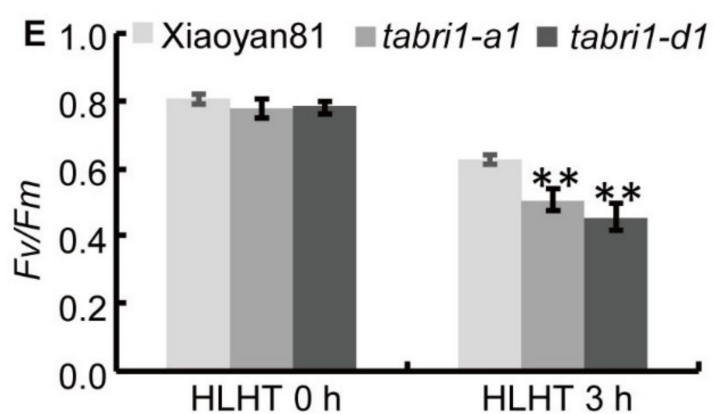

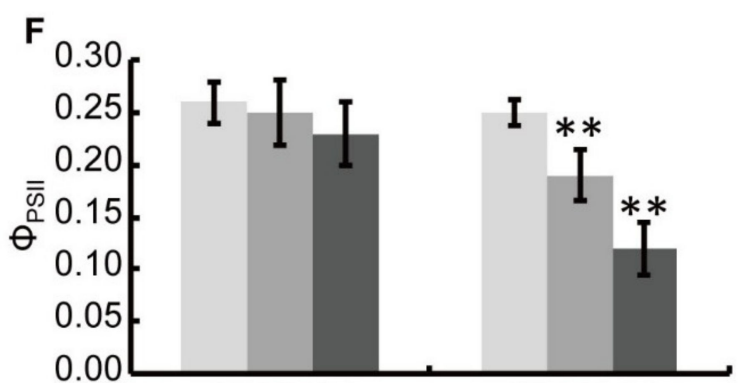

HLHT O h

HLHT 3 h

Figure 8. Chlorophyll fluorescence parameters of detached flag leaves in WT and TaBRI1 mutants at 21 DPA under HLHT $3 \mathrm{~h}$. (A-D) Images of the maximum photochemical efficiency $(F v / F m)(\mathbf{A}, \mathbf{B})$, actual PSII efficiency ( $\Phi_{\text {PSII }}$ ) (C,D) of WT and TaBRI1 mutants under HLHT $3 \mathrm{~h}$. The color in (A-D) represents the value of each parameter in the color scale; $(\mathbf{E}, \mathbf{F})$ statistical analysis of $F v / F m, \Phi_{\text {PSII }}$ in (A-D), respectively. Data are from three biologic replicates, and each biologic replicate comprised eight plants. ${ }^{* *}$ indicates significant differences between WT and TaBRI1 mutants at $p<0.01$.

To further confirm the role of TaBRI1 in wheat responses to HLHT stresses, the barley stripe mosaic virus (BSMV)-based virus-induced TaBRI1 silencing (VIGS) technique was used. The plants exhibiting significant BSMV infection symptoms were further cultured for three weeks and treated under HLHT $3 \mathrm{~h}$ (Figure 9A). The leaves with non-obvious BSMV symptoms were chosen to be measured the photosynthetic parameters (A, Gs and Ci) and the efficiency of PSII (Fv/Fm, $\Phi_{\text {PSII }}$ and ETRs) to eliminate the interference of the visible bleached leaves due to the plant immunity to virus 
(Figure 9A). The expression level of TaBRI1 in the BSMV:TaBRI1 plants was significantly decreased compared that in the BSMV:GFP plants, indicating that TaBRI1 was effectively silenced (Figure 9B). Under HLHT stresses for $3 \mathrm{~h}, \mathrm{CO}_{2}$ assimilation rate, stomatal conductance $(g s)$, intercellular $\mathrm{CO}_{2}$ partial pressure in the BSMV:TaBRI1 plants were significantly lower than those in the BSMV:GFP plants (Figure 9C-E). Meanwhile, the Fv/Fm, $\Phi_{\text {PSII }}$ and ETRs of PSII efficiency parameters in the BSMV:TaBRI1-infected plants decreased by $11.1 \%, 40.4 \%$ and $40.4 \%$, respectively compared with those in BSMV:GFP plants under HLHT $3 \mathrm{~h}$ (Figure 9F-H). In contrast, no significant differences were observed in the photosynthetic parameters (A, Gs and Ci) and the efficiency of PSII (Fv/Fm, $\Phi_{\text {PSII }}$ and ETRs) between the BSMV:GFP and BSMV:TaBRI1 plants under normal conditions (Figure 9C-H).

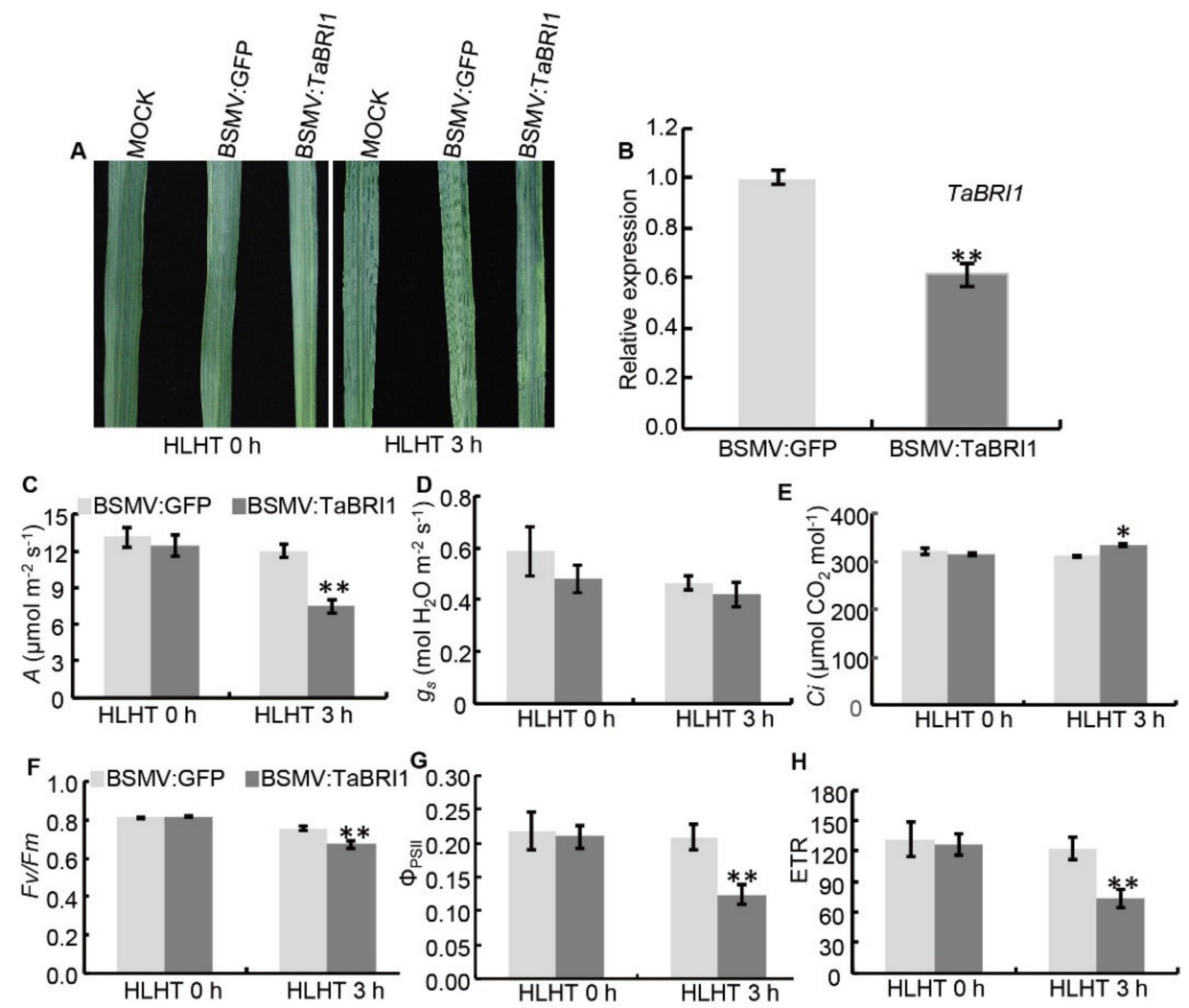

Figure 9. Responses to high light and high temperature stresses for $3 \mathrm{~h}$ (HLHT $3 \mathrm{~h}$ ) of TaBRI1-silenced plants generated by barley stripe mosaic virus (BSMV)-induced gene silencing in common wheat cv. Xiaoyan 54. (A) Leaves exhibiting mild chlorotic mosaic symptoms were treated with HLHT $3 \mathrm{~h}$ at 28 days post- inoculation (dpi) with BSMV:GFP or BSMV:TaBRI1; (B) expression levels of TaBRI1 in the BSMV:GFP and BSMV:TaBRI1 plants. Collection of the fifth leaf from eight plants of $28 \mathrm{dpi}$ was used for real-time PCR analysis. ${ }^{* *}$ indicates significant differences between BSMV:TaBRI1 and BSMV:GFP at $p<0.01 ;(\mathbf{C}-\mathbf{H})$ TaBRI1 silencing in common wheat $\mathrm{cv}$. Xiaoyan 54 reduces the tolerance to HLHT stresses. $\mathrm{CO}_{2}$ assimilation rate, $\mathrm{A}(\mathbf{C})$, stomatal conductance, gs (D), intercellular $\mathrm{CO} 2$ partial pressure, Ci (E), maximal efficiency of PSII photochemistry $(F v / F m)(\mathbf{F})$, the actual PSII efficiency $\left(\Phi_{\mathrm{PSII}}\right)(\mathrm{G})$, electron transport rates (ETRs) (H) of BSMV:GFP and BSMV:TaBRI1 plants treated with HLHT 3 h. Data from three biologic replicates, and each biologic replicate comprised eight plants. * and ${ }^{* *}$ indicate significant differences between BSMV:TaBRI1 and BSMV:GFP plants at $p<0.05$ and $p<0.01$, respectively.

\subsection{TaBRI1 Knock-Down Mutants Is Less Sensitive to Exogenous BR Treatment than Wild Type Plants}

To test whether TaBRI1 knock-down mutants, TaBRI1-A1 and TaBRI1-D1 were less sensitive to BRs than WT plants, wheat seedlings were treated with 0.1-mg/L EBR and then were subjected to HLHT stresses. As shown in Figure $10 \mathrm{~A}$, the $\mathrm{CO}_{2}$ assimilation rate of the WT seedlings was significantly 
increased by exogenously applied EBR under both normal conditions and HLHT stresses for $3 \mathrm{~h}$. However, such increase effect was not observed in the $\mathrm{CO}_{2}$ assimilation rate of the TaBRI1 knock-down mutant seedlings (Figure 10A). Considering BR signaling mutants usually have defects in feedback regulation on BR biosynthesis genes, we treated TaBRI1 knock-down mutants with or without EBR and isolated the RNA for quantitative RT-PCR analysis of BR biosynthesis gene expression, including TaDWARF4, TaCPD1 and TaCPD90D1. The results showed that the BR biosynthetic genes were significantly increased in the TaBRI1 mutants (Figure 10B). Moreover, while EBR treatment reduced the expression of these genes in WT, their expression is not decreased or decreased to a lesser extent in TaBRI1 knock-down mutants (Figure 10C). The above results suggest that there are defects in feedback regulation on BR biosynthetic genes in the TaBRI1 knock-down mutants.
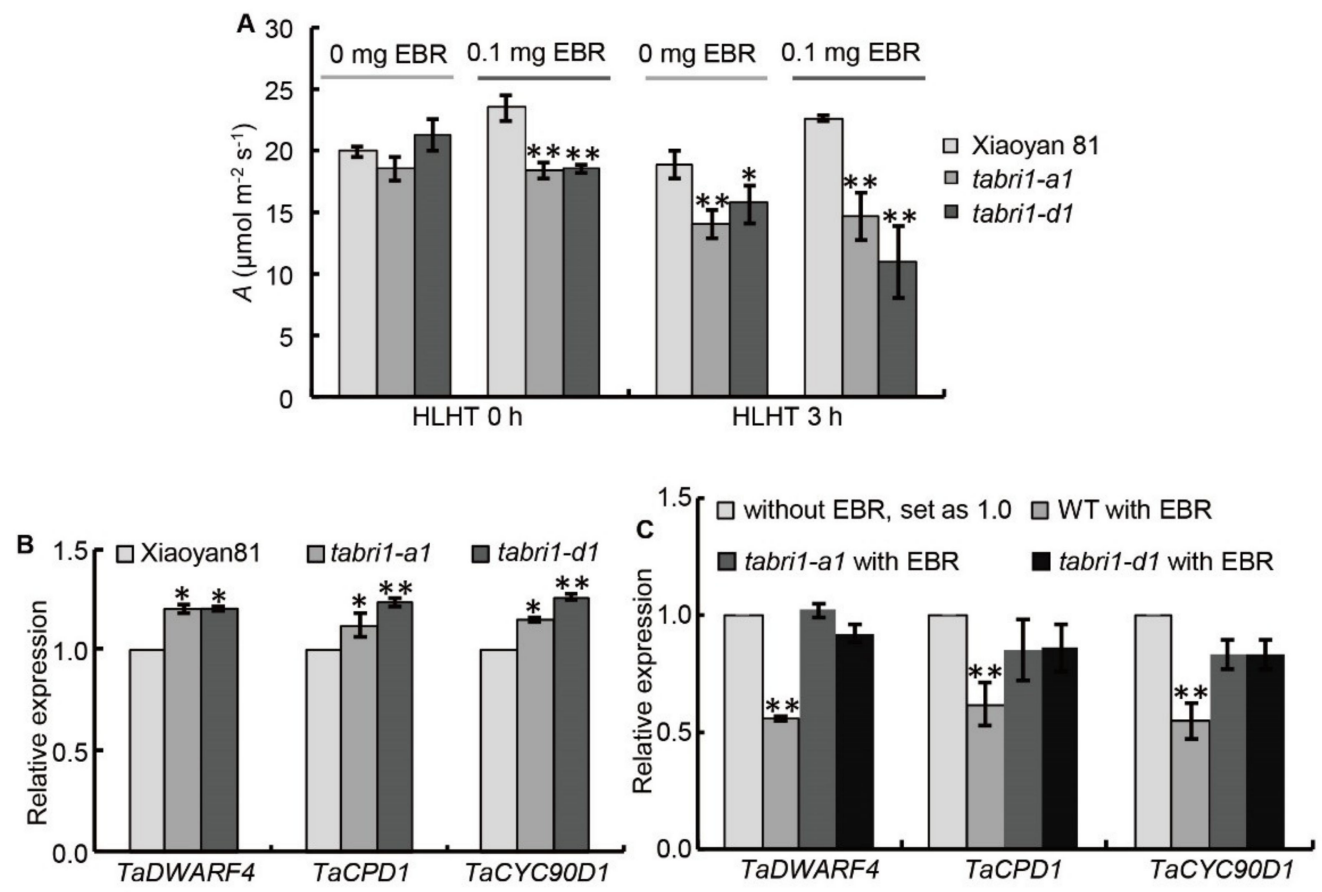

Figure 10. Effects of EBR on $\mathrm{CO}_{2}$ assimilation rate and BR-related gene expression of TaBRI1 mutants under both HLHT $0 \mathrm{~h}$ and $3 \mathrm{~h}$. (A) Effects of EBR on $\mathrm{CO}_{2}$ assimilation rate, A, of WT and TaBRI1 mutants under HLHT $3 \mathrm{~h}$. Data from three biologic replicates, and each biologic replicate comprised eight plants. * and ** indicate significant differences between WT and TaBRI1 mutants at $p<0.05$ and $p<0.01$, respectively; (B) expression of BR biosynthetic genes in WT and TaBRI1 mutants. Gene expression levels in WT are set as 1.0. Data from three biologic replicates, and each biologic replicate comprised a pool of five plants. ${ }^{*}$ and ${ }^{* *}$ indicate significant differences between WT and TaBRI1 plants at $p<0.05$ and $p<0.01$, respectively; (C) expression of BR biosynthetic genes in WT and TaBRI1 mutants with or without EBR treatment. Gene expression levels in WT without EBR treatment are set as 1.0. Data from three biologic replicates, and each biologic replicate comprised a pool of five plants.

** indicate significant differences between the control and EBR treated plants in WT at $p<0.01$.

\section{Discussion}

Although the BR signal transduction pathway in the dicot Arabidopsis and the monocot rice have been extensively studied, the understanding of BR signal transduction in wheat is poor. In this study, we identified TaBRI1-A1, -B1 and -D1 genes and functionally characterized TaBRI1 knock-down plants, TaBRI1-A1 and TaBRI1-D1, isolated from the ion beam-induced mutants of variety Xiaoyan81 which are deletion of TaBRI1-A1 and -D1, respectively. The TaBRI1 knock-down plants exhibited relatively erect leaves and a significant reduction in the 1000-grain weight. We further dissected the underlying physiological mechanisms by measuring the photosynthetic capacity and assessing the tolerance ability 
to highlight and high temperature (HLHT) stresses often suffered by wheat in Northern China Plain at the late grain filling stage.

\subsection{Knock-Down the Expression of TaBRI1 Reduced Leaf Angles and the 1000-Grain Weight}

Leaf angle, the degree of bending between the leaf blade and leaf sheath is an important factor which directly affects crop architecture and grain yields [47]. Erect leaves are desired to avoid shade and capture more light for photosynthesis when plants are grown at high planting density, all of which increase crop yields [31,32,48]. The erect leaf phenotype of TaBRI1-A1 and TaBRI1-D1 mutants can be observed as early as the seedling stage both of which showed a significant reduction in the TaBRI1 expression (Figure 3). The TaBRI1 knock-down mutants, TaBRI1-A1 and TaBRI1-D1, displayed a significant decrease in the leaf angle during the whole grain filling stage (Figure 4). d61-1 and d61-2, loss-of-function mutants of OsBRI1, showed insensitivity to BR, erect leaves and dwarf culms [6]. Similarly, barley mutant of HvBRI1, uzu, exhibited a semi-dwarf and upright plant architecture [33]. The plant height of TaBRI1-A1 and TaBRI1-D1 mutants decreased by $2.7 \%$ and $1.9 \%$, respectively compared with that of WT (Figure 5B). This reduction was far less than those in monocot plants, rice and barley. The main reason may be that BR receptor is encoded by multiple genes and has functional redundancy due to wheat as a polyploid plant. In addition, the TaBRI1-A1 and TaBRI1-D1 mutants did not show serious growth and development deficiencies which was either supposedly resulted from functional redundancy (Figure 4). The leaf angle and plant height of TaBRI1-A1 mutant was slightly lower than that of TaBRI1-D1 mutant (Figure 3C-G and Figure 4). This may be due to the functional differences in TaBRI1-A1 and -D1 proteins or differences in gene expression. In consistent, we found the expression level of total TaBRI1 was lower in TaBRI1-A1 mutant than that in the TaBRI1-D1 mutant (Figure 3A).

The grain yield of loss-of-function and brassinosteroid-deficient mutants such as $d 61$ (mutant of OsBRI1), brd1 (brassinosteroid-deficient dwarf1) and $d 2$ (defective in OsDWARF) decreased because of morphologic alterations in their reproductive development [6,25,49]. However, no significant differences were observed in the spike number per plant and number of grains per spike between WT and TaBRI1-A1 and TaBRI1-D1 mutants (Supplementary Materials Figure S4). In contrast, a significant reduction in the 1000-grain of TaBRI1 knock-down mutants were observed (Figure 5C). Previous studies have shown that the combination of erect leaves and dense planting can improve crop yield in BR-related mutants [31,50]. The TaBRI1 knock-down mutants, TaBRI1-A1 and TaBRI1-D1 showed erect leaves with a slight reduction in grain yield per plant. Thus, it was valuable to further explore whether TaBRI1 mutants have potentiality to increase crop yield in breeding under dense planting.

4.2. Knock-Down the Expression of TaBRI1 Reduced Photosynthetic Rate and the Tolerance to High Light and High Temperature Stresses

During the flowering and grain-filling stages, the $\mathrm{CO}_{2}$ assimilation rate in the flag leaf of TaBRI1 knock-down mutants, TaBRI1-A1 and TaBRI1-D1 was lower than that of WT, suggesting that BR receptor TaBRI1 was involved in the regulation of photosynthesis in wheat (Figure 6). Photosynthetic products contributed more than $90 \%$ of crop biomass [51]. In addition, when other genetic factors are not altered, there was a close relationship between enhanced photosynthesis, biomass and yield [52]. Thus, it may be a possible reason for the significant reduction in the 1000-grain that the decreased $\mathrm{CO}_{2}$ assimilation rate during the whole grain filling stage in TaBRI1 knock-down mutants (Figures 5C and 6). Recent study showed that autophosphorylation inhibition of the tyrosine-831 in BRI1 receptor kinase could increase the maximum carboxylation rate of Rubisco and promote the regeneration of RuBP, leading to an enhancement of shoot growth [53]. It remains further to be studied how the photosynthesis is regulated by BR signal transduction in the TaBRI1 knock-down mutants. Kim et al. (2010) found that some genes encoding chloroplast-localized proteins were downregulated in the cold-resistant bri1 mutant [54]. Therefore, it was either believed that the lack of chloroplast assembly, especially the assembly of light system II, possibly led to the decrease of photosynthetic rate in TaBRI1 knock-down mutants. 
High light at noon in sunny days often inhibits $\mathrm{CO}_{2}$ assimilation rate in flag leaves, thus leading to approximately $10 \%$ loss of potential carbon assimilation under natural conditions [55]. Other adverse environments such as high temperature and/or drought during the grain filling period will eventually change the reversible photoinhibition into irreversible photooxidation of photosynthetic apparatus which will result in a decrease in photosynthetic function [45]. Wheat plants often suffer high light and high temperature (HLHT) stresses at the late grain filling stage in Northern China Plain. Thus, we speculated there may be some relationship between the tolerance to HLHT stresses and the decrease of photosynthetic function in the TaBRI1 knock-down mutants. In our study, it was indeed found that the photosynthetic rate and maximum photochemical efficiency $(F v / F m)$ in TaBRI1-A1 and TaBRI1-D1 mutants were obviously lower than those in WT Xiaoyan81 after HLHT three hours, indicating the TaBRI1-A1 and TaBRI1-D1 mutants are more sensitive to HLHT stresses than WT (Figures 7, 8, 9 and 10A). In consistent, previous studies showed that overexpression of TaBRI1 in Arabidopsis showed thermo tolerance phenotype at the seedling stage with increased chlorophyll content, photosystem II activity and membrane stability [56]. However, the bri1-9 mutant, a dwarf mutant caused by defective BR signaling, exhibited an increased tolerance to cold stress due to it could always be alert to stresses by constitutive activation of subsets of defense [54]. Different from bri1- 9 mutant tolerant to cold stress, TaBRI1-A1 and TaBRI1-D1 mutants were not resistant to HLHT stresses possibly due to the lack of constitutive activation of defense responses. The other possible reason may be the difference in defense mechanism of cold stress and HLHT stresses. We also observed that foliar spraying EBR significantly increased the photosynthetic rate and the tolerance to HLHT stresses in WT Xiaoyan81. Compared with that, EBR spraying had no effects on the photosynthetic rate and the tolerance to HLHT stresses in TaBRI1-A1 and TaBRI1-D1 mutants. Moreover, the photosynthetic rate of TaBRI1-A1 and TaBRI1-D1 mutants was decreased by spraying EBR under HLHT stresses (Figure 10A). Yu et al. (2004) demonstrated that $10^{-8} \mathrm{M}$ or $10^{-7}$-M EBR effectively improve photosynthetic rate and high concentration of EBR has no effect on photosynthetic efficiency [57]. Therefore, excessive concentration of EBR treatment has no favor to plant resistance to stresses. The BR biosynthetic genes were significantly increased under normal conditions and is not decreased or decreased to a lesser extent after EBR treatment in TaBRI1 knock-down mutants due to the defects in feedback regulation on BR biosynthesis genes (Figure 10B,C). Supposedly, TaBRI1 knock-down mutants may accumulate more BR, thus 0.1-mg/L EBR application may be too high for the mutants to confer the resistance to HLHT stresses.

\section{Conclusions}

In summary, we found exogenous BR treatment induced the tolerance to high light and high temperature stresses in wheat seedlings. To explore the detailed mechanisms of BR signaling in high light and high temperature stresses response in wheat. We cloned three BRI1 homologous genes TaBRI1-A1, $-B 1$ and $-D 1$ from hexaploid wheat (Triticum estivum L.) and further isolated the TaBRI1 knock-down mutants from the ion beam-induced mutants of variety Xiaoyan81, TaBRI1-A1 and TaBRI1-D1. TaBRI1 knockdown plants generated by TaBRI1-A1, TaBRI1-D1 deletion or using virus-induced gene silencing exhibited the reduction in the photosynthetic parameters (A, Gs and $\mathrm{Ci}$ ) and the efficiency of PSII ( $F v / F m, \Phi I I$ and ETR) especially under high light and high temperature stresses. The TaBRI1 knock-down mutants exhibited relatively erect leaves and a significant reduction in the 1000-grain weight probably because of the reduced photosynthetic rate and tolerance to high light and high temperature stresses. Further efforts will be directed to understand the detailed molecular mechanisms of TaBRI1 and the signaling pathway involved in regulating these processes. 
Supplementary Materials: The following are available online at http://www.mdpi.com/2223-7747/9/7/840/s1, Figure S1: Multiple alignment of deduced amino acid sequence of TaBRI1 of A (TaBRI1-A1), B (TaBRI1-B1) and D (TaBRI1-D1) genomes; Figure S2: The leaf angle in the wild type (WT), TaBRI1 mutants and corresponding $\mathrm{BC}_{1} \mathrm{~F}_{2}$ homozygous individuals for TaBRI1 deletion identified with TaBRI1-A1 and TaBRI1-D1 specific primers at 14 DPA; Figure S3: The root length of WT and TaBRI1 mutants at seedling stage; Figure S4: The yield traits in WT, TaBRI1 mutants; Figure S5: Photosynthesis parameters in WT and TaBRI1 mutants during the whole post-anthesis period; Table S1: Primers used in this work.

Author Contributions: Y.T. conceived and designed research. J.F. conducted experiments, analyzed data and wrote the manuscript. W.Z. contributed to the field experiments. All authors have read and agreed to the published version of the manuscript.

Funding: This research was funded by the Strategic Priority Research Program of Chinese Academy of Sciences, Grant No. XDA24010202.

Acknowledgments: We thank Daowen Wang (Institute of Genetics and Developmental Biology) for kindly supplying the Xiaoyan81 deletion mutant library.

Conflicts of Interest: The authors declare no conflict of interest.

\section{References}

1. Murchie, E.H.; Pinto, M.; Horton, P. Agriculture and the new challenges for photosynthesis research. New Phytol. 2009, 181, 532-552. [CrossRef] [PubMed]

2. Zhang, C.; Bai, M.Y.; Chong, K. Brassinosteroid-mediated regulation of agronomic traits in rice. Plant Cell Rep. 2014, 33, 683-696. [CrossRef] [PubMed]

3. Singh, A.P.; Savaldigoldstein, S. Growth control: Brassinosteroid activity gets context. J. Exp. Bot. 2015, 66, 1123. [CrossRef]

4. Vert, G.; Nemhauser, J.L.; Geldner, N.; Hong, F.; Chory, J. Molecular mechanisms of steroid hormone signaling in plants. Annu. Rev. Cell Dev. Biol. 2005, 21, 177-201. [CrossRef]

5. Tong, H.; Chu, C. Functional Specificities of Brassinosteroid and Potential Utilization for Crop Improvement. Trends Plant Sci. 2018, 23, 1016-1028. [CrossRef] [PubMed]

6. Yamamuro, C.; Ihara, Y.; Wu, X.; Noguchi, T.; Fujioka, S.; Takatsuto, S.; Ashikari, M.; Kitano, H.; Matsuoka, M. Loss of function of a rice brassinosteroid insensitive1 homolog prevents internode elongation and bending of the lamina joint. Plant Cell 2000, 12, 1591-1605. [CrossRef]

7. Li, D.; Wang, L.; Wang, M.; Xu, Y.Y.; Luo, W.; Liu, Y.J.; Xu, Z.H.; Li, J.; Chong, K. Engineering OsBAK1 gene as a molecular tool to improve rice architecture for high yield. Plant Biotechnol. J. 2009, 7, 791-806. [CrossRef] [PubMed]

8. Jaillais, Y.; Hothorn, M.; Belkhadir, Y.; Dabi, T.; Nimchuk, Z.L.; Meyerowitz, E.M.; Chory, J. Tyrosine phosphorylation controls brassinosteroid receptor activation by triggering membrane release of its kinase inhibitor. Gene Dev. 2011, 25, 232-237. [CrossRef]

9. Li, J.; Wen, J.; Lease, K.A.; Doke, J.T.; Tax, F.E.; Walker, J.C. BAK1, an Arabidopsis LRR Receptor-like Protein Kinase, Interacts with BRI1 and Modulates Brassinosteroid Signaling. Cell 2002, 110, 213-222. [CrossRef]

10. Tong, H.N.; Liu, L.C.; Jin, Y.; Du, L.; Yin, Y.H.; Qian, Q.; Zhu, L.H.; Chu, C.C. DWARF AND LOW-TILLERING Acts as a Direct Downstream Target of a GSK3/SHAGGY-Like Kinase to Mediate Brassinosteroid Responses in Rice. Plant Cell 2012, 24, 2562-2577. [CrossRef]

11. Tang, W.Q.; Yuan, M.; Wang, R.J.; Yang, Y.H.; Wang, C.M.; Oses-Prieto, J.A.; Kim, T.W.; Zhou, H.W.; Deng, Z.P.; Gampala, S.S.; et al. PP2A activates brassinosteroid-responsive gene expression and plant growth by dephosphorylating BZR1. Nat. Cell Biol. 2011, 13, 124-131. [CrossRef] [PubMed]

12. Xia, X.J.; Huang, L.F.; Zhou, Y.H.; Mao, W.H.; Shi, K.; Wu, J.X.; Asami, T.; Chen, Z.X.; Yu, J.Q. Brassinosteroids promote photosynthesis and growth by enhancing activation of Rubisco and expression of photosynthetic genes in Cucumis sativus. Planta 2009, 230, 1185-1196. [CrossRef] [PubMed]

13. Zhang, M.C.; Zhai, Z.X.; Tian, X.L.; Duan, L.S.; Li, Z.H. Brassinolide alleviated the adverse effect of water deficits on photosynthesis and the antioxidant of soybean (Glycine max L.). Plant Growth Regul. 2008, 56, 257-264. [CrossRef]

14. Shahbaz, M.; Ashraf, M.; Athar, H.U.R. Does exogenous application of 24-epibrassinolide ameliorate salt induced growth inhibition in wheat (Triticum aestivum L.)? Plant Growth Regul. 2008, 55, 51-64. [CrossRef] 
15. Ahammed, G.J.; Yuan, H.L.; Ogweno, J.O.; Zhou, Y.H.; Xia, X.J.; Mao, W.H.; Shi, K.; Yu, J.Q. Brassinosteroid alleviates phenanthrene and pyrene phytotoxicity by increasing detoxification activity and photosynthesis in tomato. Chemosphere 2012, 86, 546-555. [CrossRef]

16. Sharma, I.; Pati, P.K.; Bhardwaj, R. Effect of 24-epibrassinolide on oxidative stress markers induced by nickel-ion in Raphanus sativus L. Acta Physiol. Plant 2011, 33, 1723-1735. [CrossRef]

17. Gururani, M.A.; Mohanta, T.K.; Bae, H. Current understanding of the interplay between phytohormones and photosynthesis under environmental stress. Int. J. Mol. Sci. 2015, 16, 19055-19085. [CrossRef] [PubMed]

18. Takahashi, S.; Murata, N. How do environmental stresses accelerate photoinhibition? Trends Plant Sci. 2008, 13, 178-182. [CrossRef]

19. Anjum, S.A.; Wang, L.C.; Farooq, M.; Hussain, M.; Xue, L.L.; Zou, C.M. Brassinolide Application Improves the Drought Tolerance in Maize Through Modulation of Enzymatic Antioxidants and Leaf Gas Exchange. J. Agron. Crop Sci. 2011, 197, 177-185. [CrossRef]

20. Friebe, A. Brassinosteroids in induced resistance and induction of tolerances to abiotic stress in plants. In Natural Products for Pest Management; American Chemical Society: Washington, DC, USA, 2006; Volume 927, pp. 233-242. [CrossRef]

21. Sonjaroon, W.; Jutamanee, K.; Khamsuk, O.; Thussagunpanit, J.; Kaveeta, L.; Suksamrarn, A. Impact of brassinosteroid mimic on photosynthesis, carbohydrate content and rice seed set at reproductive stage under heat stress. Agric. Nat. Resour. 2018, 52, 234-240. [CrossRef]

22. Sharma, I.; Kaur, N.; Pati, P.K. Brassinosteroids: A Promising Option in Deciphering Remedial Strategies for Abiotic Stress Tolerance in Rice. Front. Plant Sci. 2017, 8, 2151. [CrossRef] [PubMed]

23. Cui, F.; Liu, L.J.; Zhao, Q.Z.; Zhang, Z.H.; Li, Q.L.; Lin, B.Y.; Wu, Y.R.; Tang, S.Y.; Xie, Q. Arabidopsis Ubiquitin Conjugase UBC32 Is an ERAD Component That Functions in Brassinosteroid-Mediated Salt Stress Tolerance. Plant Cell 2012, 24, 233-244. [CrossRef] [PubMed]

24. Lv, M.; Li, M.; Chen, W.; Wang, Y.; Sun, C.; Yin, H.; He, K.; Li, J. Thermal-Enhanced bri1-301 Instability Reveals a Plasma Membrane Protein Quality Control System in Plants. Front. Plant Sci. 2018, 9, 1620. [CrossRef] [PubMed]

25. Hong, Z.; Ueguchi-Tanaka, M.; Umemura, K.; Uozu, S.; Fujioka, S.; Takatsuto, S.; Yoshida, S.; Ashikari, M.; Kitano, H.; Matsuoka, M. A rice brassinosteroid-deficient mutant, ebisu dwarf (d2), is caused by a loss of function of a new member of cytochrome P450. Plant Cell 2003, 15, 2900-2910. [CrossRef] [PubMed]

26. Hong, Z.; Ueguchi-Tanaka, M.; Fujioka, S.; Takatsuto, S.; Yoshida, S.; Hasegawa, Y.; Ashikari, M.; Kitano, H.; Matsuoka, M. The Rice brassinosteroid-deficient dwarf2 mutant, defective in the rice homolog of Arabidopsis DIMINUTO/DWARF1, is rescued by the endogenously accumulated alternative bioactive brassinosteroid, dolichosterone. Plant Cell 2005, 17, 2243-2254. [CrossRef]

27. Tanabe, S.; Ashikari, M.; Fujioka, S.; Takatsuto, S.; Yoshida, S.; Yano, M.; Yoshimura, A.; Kitano, H.; Matsuoka, M.; Fujisawa, Y.; et al. A novel cytochrome P450 is implicated in brassinosteroid biosynthesis via the characterization of a rice dwarf mutant, dwarf11, with reduced seed length. Plant Cell 2005, 17, 776-790. [CrossRef]

28. Tanaka, A.; Nakagawa, H.; Tomita, C.; Shimatani, Z.; Ohtake, M.; Nomura, T.; Jiang, C.J.; Dubouzet, J.G.; Kikuchi, S.; Sekimoto, H.; et al. BRASSINOSTEROID UPREGULATED1, Encoding a Helix-Loop-Helix Protein, Is a Novel Gene Involved in Brassinosteroid Signaling and Controls Bending of the Lamina Joint in Rice. Plant Physiol. 2009, 151, 669-680. [CrossRef]

29. Choe, S.; Fujioka, S.; Noguchi, T.; Takatsuto, S.; Yoshida, S.; Feldmann, K.A. Overexpression of DWARF4 in the brassinosteroid biosynthetic pathway results in increased vegetative growth and seed yield in Arabidopsis. Plant J. 2001, 26, 573-582. [CrossRef]

30. Wu, C.Y.; Trieu, A.; Radhakrishnan, P.; Kwok, S.F.; Harris, S.; Zhang, K.; Wang, J.L.; Wan, J.M.; Zhai, H.Q.; Takatsuto, S.; et al. Brassinosteroids regulate grain filling in rice. Plant Cell 2008, 20, 2130-2145. [CrossRef]

31. Sakamoto, T.; Morinaka, Y.; Ohnishi, T.; Sunohara, H.; Fujioka, S.; Ueguchi-Tanaka, M.; Mizutani, M.; Sakata, K.; Takatsuto, S.; Yoshida, S.; et al. Erect leaves caused by brassinosteroid deficiency increase biomass production and grain yield in rice. Nat. Biotechnol. 2006, 24, 105-109. [CrossRef] [PubMed]

32. Morinaka, Y.; Sakamoto, T.; Inukai, Y.; Agetsuma, M.; Kitano, H.; Ashikari, M.; Matsuoka, M. Morphological alteration caused by brassinosteroid insensitivity increases the biomass and grain production of rice. Plant Physiol. 2006, 141, 924-931. [CrossRef] 
33. Chono, M.; Honda, I.; Zeniya, H.; Yoneyama, K.; Saisho, D.; Takeda, K.; Takatsuto, S.; Hoshino, T.; Watanabe, Y. A semidwarf phenotype of barley $u z u$ results from a nucleotide substitution in the gene encoding a putative brassinosteroid receptor. Plant Physiol. 2003, 133, 1209-1219. [CrossRef] [PubMed]

34. Koka, C.V.; Cerny, R.E.; Gardner, R.G.; Noguchi, T.; Fujioka, S.; Takatsuto, S.; Yoshida, S.; Clouse, S.D. A putative role for the tomato genes DUMPY and CURL-3 in brassinosteroid biosynthesis and response. Plant Physiol. 2000, 122, 85-98. [CrossRef] [PubMed]

35. Nomura, T.; Bishop, G.J.; Kaneta, T.; Reid, J.B.; Chory, J.; Yokota, T. The LKA gene is a BRASSINOSTEROID INSENSITIVE 1 homolog of pea. Plant J. 2003, 36, 291-300. [CrossRef] [PubMed]

36. Goddard, R.; Peraldi, A.; Ridout, C.; Nicholson, P. Enhanced disease resistance caused by BRI1 mutation is conserved between Brachypodium distachyon and barley (Hordeum vulgare). Mol. Plant Microbe Interact. 2014, 27, 1095-1106. [CrossRef]

37. Yang, Y.; Li, S.; Zhang, K.; Dong, Z.; Li, Y.; An, X.; Chen, J.; Chen, Q.; Jiao, Z.; Liu, X.; et al. Efficient isolation of ion beam-induced mutants for homoeologous loci in common wheat and comparison of the contributions of Glu-1 loci to gluten functionality. Theor. Appl. Genet. 2014, 127, 359-372. [CrossRef]

38. Ren, Y.Z.; He, X.; Liu, D.C.; Li, J.J.; Zhao, X.Q.; Li, B.; Tong, Y.P.; Zhang, A.M.; Li, Z.S. Major quantitative trait loci for seminal root morphology of wheat seedlings. Mol. Breed. 2012, 30, 139-148. [CrossRef]

39. Saitou, N.; Nei, M. The neighbor-joining method: A new method for reconstructing phylogenetic trees. Mol. Biol. Evol. 1987, 4, 406-425. [CrossRef]

40. Petty, I.T.; Hunter, B.G.; Wei, N.; Jackson, A.O. Infectious barley stripe mosaic virus RNA transcribed in vitro from full-length genomic cDNA clones. Virology 1989, 171, 342-349. [CrossRef]

41. Lu, C.; Qiu, N.; Wang, B.; Zhang, J. Salinity treatment shows no effects on photosystem II photochemistry, but increases the resistance of photosystem II to heat stress in halophyte Suaeda salsa. J. Exp. Bot. 2003, 54, 851-860. [CrossRef]

42. Cui, K.H.; Peng, S.B.; Xing, Y.Z.; Yu, S.B.; Xu, C.G.; Zhang, Q. Molecular dissection of the genetic relationships of source, sink and transport tissue with yield traits in rice. Theor. Appl. Genet. 2003, 106, 649-658. [CrossRef] [PubMed]

43. Mei, H.W.; Luo, L.J.; Ying, C.S.; Wang, Y.P.; Yu, X.Q.; Guo, L.B.; Paterson, A.H.; Li, Z.K. Gene actions of QTLs affecting several agronomic traits resolved in a recombinant inbred rice population and two testcross populations. Theor. Appl. Genet. 2003, 107, 89-101. [CrossRef] [PubMed]

44. Wang, P.; Zhou, G.; Yu, H.; Yu, S. Fine mapping a major QTL for flag leaf size and yield-related traits in rice. Theor. Appl. Genet. 2011, 123, 1319-1330. [CrossRef] [PubMed]

45. Gladun, I.V.; Karpov, E.A. Distribution of assimilates from the flag leaf of rice during the reproductive period of development. Russ. J. Plant Physiol. 1993, 40, 215-218.

46. Long, S.P.; Humphries, S.; Falkowski, P.G. Photoinhibition of Photosynthesis in Nature. Annu. Rev. Plant Physiol. Plant Mol. Biol. 1994, 45, 633-655. [CrossRef]

47. Sinclair, T.R.; Sheehy, J.E. Erect Leaves and Photosynthesis in Rice. Science 1999, 283, 1455. [CrossRef]

48. Wu, X.; Tang, D.; Li, M.; Wang, K.; Cheng, Z. Loose Plant Architecture1, an INDETERMINATE DOMAIN protein involved in shoot gravitropism, regulates plant architecture in rice. Plant Physiol. 2013, 161, 317-329. [CrossRef]

49. Hong, Z.; Ueguchi-Tanaka, M.; Shimizu-Sato, S.; Inukai, Y.; Fujioka, S.; Shimada, Y.; Takatsuto, S.; Agetsuma, M.; Yoshida, S.; Watanabe, Y.; et al. Loss-of-function of a rice brassinosteroid biosynthetic enzyme, C-6 oxidase, prevents the organized arrangement and polar elongation of cells in the leaves and stem. Plant J. 2002, 32, 495-508. [CrossRef]

50. Wu, C.Y.; Kwok, S.; Harris, S.; Trieu, A.; Radhakrishnan, P.; Salazar, A.; Zhang, K.; Wang, J.L.; Wan, J.M.; Fujioka, S.; et al. Enhancement of the Brassinosteroid Biosynthesis Pathway Improves Grain Yield in Rice. In Biotechnology and Sustainable Agriculture 2006 and Beyond; Springer: Dordrecht, The Netherlands, 2007; pp. 319-322.

51. Makino, A. Photosynthesis, grain yield, and nitrogen utilization in rice and wheat. Plant Physiol. 2011, 155, 125-129. [CrossRef]

52. Long, S.P.; Zhu, X.G.; Naidu, S.L.; Ort, D.R. Can improvement in photosynthesis increase crop yields? Plant Cell Environ. 2006, 29, 315-330. [CrossRef] 
53. Oh, M.H.; Clouse, S.D.; Huber, S.C. Tyrosine phosphorylation of the BRI1 receptor kinase occurs via a post-translational modification and is activated by the juxtamembrane domain. Front. Plant Sci. 2012, 3, 175. [CrossRef] [PubMed]

54. Kim, S.Y.; Kim, B.H.; Nam, K.H. Reduced expression of the genes encoding chloroplast-localized proteins in a cold-resistant bri1 (brassinosteroid-insensitive 1) mutant. Plant Signal. Behav. 2010, 5, 458-463. [CrossRef]

55. Ogren, E.; Rosenqvist, E. On the significance of photoinhibition of photosynthesis in the field and its generality among species. Photosynth. Res. 1992, 33, 63-71. [CrossRef] [PubMed]

56. Singh, A.; Breja, P.; Khurana, J.P.; Khurana, P. Wheat Brassinosteroid-Insensitive1 (TaBRI1) Interacts with Members of TaSERK Gene Family and Cause Early Flowering and Seed Yield Enhancement in Arabidopsis. PLOS ONE 2016, 11, e0153273. [CrossRef]

57. Yu, J.Q.; Huang, L.F.; Hu, W.H.; Zhou, Y.H.; Mao, W.H.; Ye, S.F.; Nogues, S. A role for brassinosteroids in the regulation of photosynthesis in Cucumis sativus. J. Exp. Bot. 2004, 55, 1135-1143. [CrossRef] [PubMed]

(C) 2020 by the authors. Licensee MDPI, Basel, Switzerland. This article is an open access article distributed under the terms and conditions of the Creative Commons Attribution (CC BY) license (http://creativecommons.org/licenses/by/4.0/). 